\title{
Tris(acetylacetonato) Iron(III): Recent Developments and Synthetic Applications
}

\author{
Dennis Lübken ${ }^{\mathrm{a}, \mathrm{b}}$ \\ Marius Saxarra ${ }^{a, b}$ \\ Markus Kalesse*a,b,c (D) \\ a Leibniz Universität Hannover, Institute of Organic Chemistry, \\ Schneiderberg 1B, 30167 Hannover, Germany \\ markus.kalesse@oci.uni-hannover.de \\ ' Leibniz Universität Hannover, Centre for Biomolecular Drug \\ Research (BMWZ), Schneiderberg 38, 30167 Hannover, \\ Germany \\ ' Helmholtz Centre for Infection Research (HZI), Imhoffenstr. 7 ,
}

38124 Braunschweig, Germany

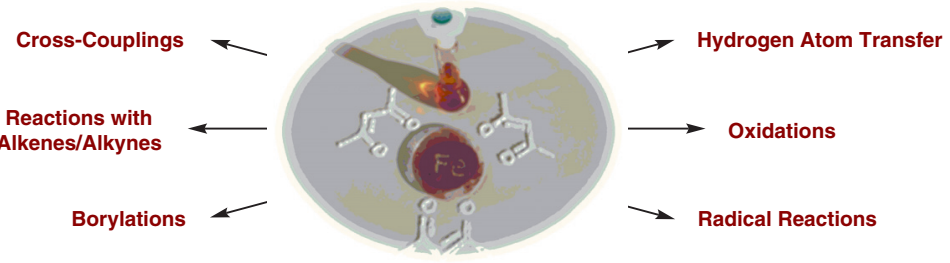

This paper is dedicated to Dr. Holger Butenschön (Leibniz Universität Hannover) on the occasion of his $65^{\text {th }}$ birthday.

Published as part of the 50 Years SYNTHESIS - Golden Anniversary Issue

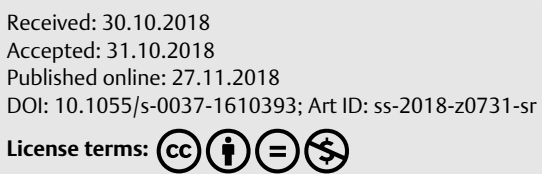

Abstract Tris(acetylacetonato) iron(III) $\left[\mathrm{Fe}(\mathrm{acac})_{3}\right]$ is an indispensable reagent in synthetic chemistry. Its applications range from hydrogen atom transfer to cross-coupling reactions and to use as a Lewis acid. Consequently, the exceptional utility of $\mathrm{Fe}(\mathrm{acac})_{3}$ has been demonstrated in several total syntheses. This short review summarizes the applications of $\mathrm{Fe}(\mathrm{acac})_{3}$ in methodology and catalysis and highlights its use for the synthesis of medicinally relevant structures and in natural product syntheses.

Introduction

Hydrogen Atom Transfer (HAT)

Oxidations and Radical Transformations

Synthesis and Use of Alkynes and Allenes

Cross-Couplings and Cycloisomerizations

Borylations

Miscellaneous Reactions

Conclusions

Key words $\mathrm{Fe}(\mathrm{acac})_{3}$, tris(acetylacetonato) iron(III), hydrogen atom transfer, radical transformations, cross-couplings, synthetic chemistry, catalysis

\section{Introduction}

Being the fourth most abundant element in the Earth's crust, iron possesses various redox properties leading to oxidation states from - II to + VI, with the oxidation states + II and +III being the most favored. The role of iron ${ }^{1}$ in synthetic organic chemistry has undergone significant transformation, in particular, its use in homogeneous catalysis has changed the view on iron as a non-noble metal. ${ }^{2}$ For decades, the acetylacetonate salt of iron(III), $\mathrm{Fe}(\mathrm{acac})_{3}$, has

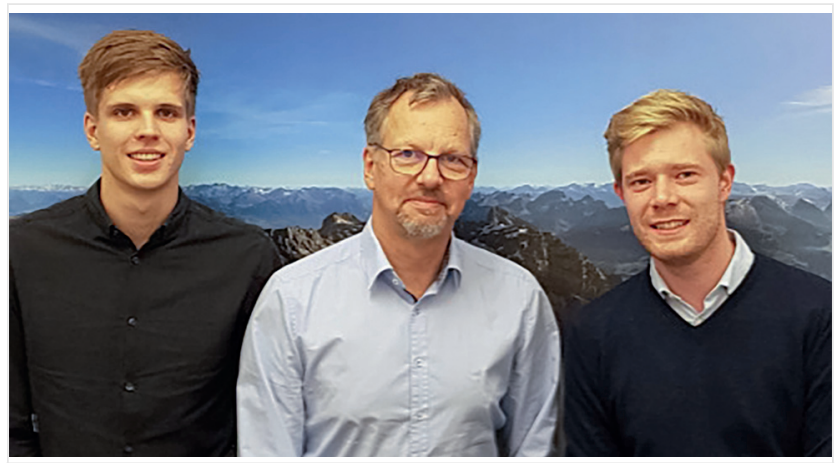

Markus Kalesse (middle) received his diploma and Ph.D. under the guidance of Prof. Dieter Schinzer at the University of Hannover, Germany. After a postdoctoral stay with Prof. Steven D. Burke and Prof. Laura L. Kiessling at the University of Wisconsin-Madison, he returned to Hannover to receive his venia legendi in organic chemistry. In 2002, he was appointed full professor at the Free University of Berlin and returned to Hannover in 2003. Since 2005 he has been the Director of the Medicinal Chemistry Department of the Helmholtz Centre for Infection Research ( $\mathrm{HZI}$ ) in Braunschweig.

Dennis Lübken (right) received his B.Sc. in chemistry (2014) from the University of Oldenburg, Germany and his M.Sc. (2016) in medicinal and natural product chemistry from the University of Hannover. He undertook a research internship in the laboratories of Prof. Cesare Gennari at the University of Milan, Italy from 2015 to 2016. Currently, he is studying as a Ph.D. student in the field of total synthesis and synthetic methodology with Prof. Markus Kalesse.

Marius Saxarra (left) received his B.Sc. in chemistry (2016) and M.Sc (2018) in medicinal and natural product chemistry from the University of Hannover. He is currently a Ph.D. student studying in the field of total synthesis and synthetic methodology with Prof. Markus Kalesse.

played a major role in synthetic chemistry. Tris(acetylacetonato) iron(III) is a deep-red crystalline solid with good solubility in alcoholic and chlorinated solvents. Several protocols for the synthesis ${ }^{3}$ and purification ${ }^{3}$ of $\mathrm{Fe}(\mathrm{acac})_{3}$ are 
available in the literature, even videos with practical guidance for laboratory praxis are available on YouTube. Different types of reactions and synthetic procedures have been used and reported over the last decades. The use of $\mathrm{Fe}(\mathrm{acac})_{3}$ in synthetic organic methodology and natural product total synthesis is fairly broad. In this short review, we will focus on the recent contributions in the fields of radical transformations, hydrogen atom transfers from in situ generated iron hydride species, carbometalations and cross-couplings.

\section{Hydrogen Atom Transfer (HAT)}

In the recent past, $\mathrm{Fe}(\mathrm{acac})_{3}$ in combination with wellknown reducing agents such as silanes has evolved to be an efficient hydrogen atom donor catalyst for the reductive mediation of radical reactions. In 1989, pioneering work on selective functionalizations of electron-rich or non-activated olefins was published by Mukaiyama ${ }^{4}$ working on $\mathrm{Co}(\mathrm{acac})_{2}$-catalyzed hydration reactions of non-activated olefins. This class of reactions is based on hydrogen atom transfer (most likely $\mathrm{H}$-atom, no hydride or proton transfer $)^{5}$ from transition-metal hydride species 1 to electronrich olefins, and by so doing, generating the desired reactivity for subsequent transformations (Scheme 1). Up to now, feasible reaction partners for HAT-initiated reactions are olefins, Michael acceptors, nitroarenes, sulfonyl hydrazones, heteroarenes and heteroarene $N$-oxides. Furthermore, radical driven isomerizations and cyclizations of alkene-tethered ketones are reported.

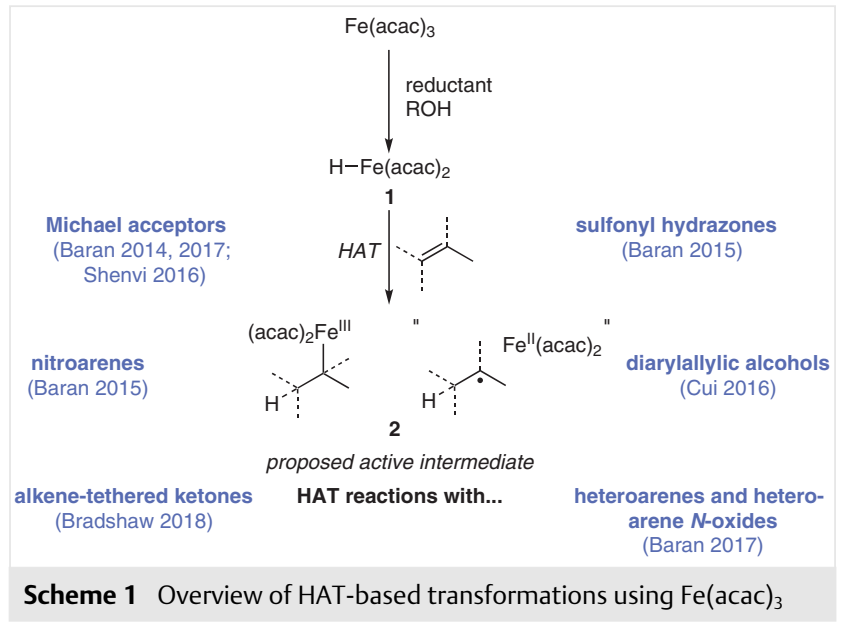

In 2014, Baran and co-workers ${ }^{6}$ published reductive olefin couplings of electron-rich donor olefins 3 and electrondeficient acceptor olefins 4 (Scheme 2). ${ }^{6}$ These types of reactions are based on HATs onto donor olefins 3 to generate radicals of nucleophilic character to add in a 1,4-addition fashion. This addition to acceptor olefins $\mathbf{4}$ results in the formation of a new carbon-carbon single bond. The reac- tion pathway for the addition of nucleophilic radicals to electron-withdrawing olefins was studied with numerous model and deuteration experiments. Baran's group deconvoluted the role of all the reagents and reaction parameters revealing the importance of an alcoholic solvent. ${ }^{6 c}$

(a) Reductive Olefin Coupling (Baran 2014, 2017)

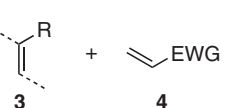

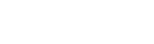

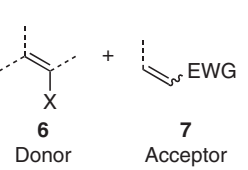<smiles>[R]C(C)(CC)CCC(C)C</smiles>

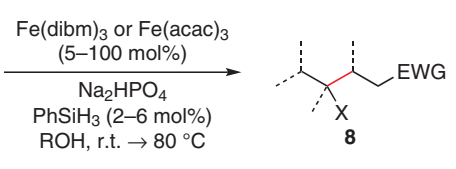

(b) Synthetic examples (Baran 2014)

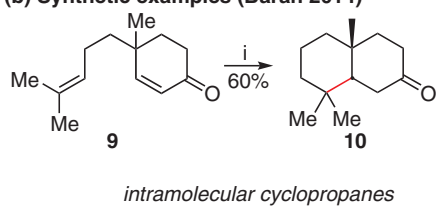<smiles>CC(=O)CC1C2C(C)(C)CCCC1(C)C21CCCCC1(C)C(C)=O</smiles>

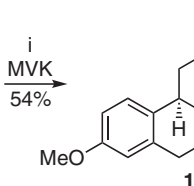

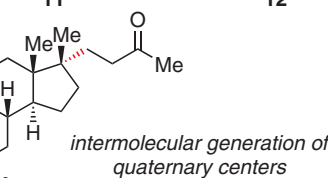

quaternary centers
Scheme 2 (a) General scheme for reductive olefin couplings including optimal reaction conditions (EWG: aldehyde, ketone, ester, nitrile, amide, sulfone; $\mathrm{X}=\mathrm{O}, \mathrm{N}, \mathrm{S}, \mathrm{B}, \mathrm{Si}$, halide), and (b) synthetic examples from the Baran laboratories. ${ }^{6}$ (i) $\mathrm{Fe}(\mathrm{acac})_{3}, \mathrm{PhSiH}_{3}, \mathrm{EtOH}, \mathrm{HO}\left(\mathrm{CH}_{2}\right)_{2} \mathrm{OH}, 60^{\circ} \mathrm{C}$.

The combination of $\mathrm{Fe}(\mathrm{acac})_{3}$ and phenylsilane in the presence of an alcoholic solvent at elevated temperatures was described by Baran as the optimal combination for such reductive olefin couplings (Scheme 2). ${ }^{6}$ These conditions are compatible with numerous functional groups on the donor olefin $\mathbf{6}$ and tolerate a variety of electron-withdrawing groups on the acceptor 7. $^{6}$ This process has been developed for the synthesis of rosthorin A, which is a kaurane diterpenoid, and its synthesis was split into a cyclization phase (selective $\mathrm{C}-\mathrm{C}$ bond formations) and an oxidation phase (selective $\mathrm{C}-\mathrm{O}$ bond formation). ${ }^{6}$ This reductive olefin coupling now opens inspiring and fascinating possibilities for disconnections during the cyclization phases., The synthesis of decalin $\mathbf{1 0}$ was one of the first examples of an intramolecular HAT reaction provided amongst a variety of others in the pivotal paper ${ }^{6 a}$ published by the Baran group (Scheme 2). ${ }^{6}$ Moreover, it has been shown that even cyclopropanes 12 can be obtained in excellent yields using the described transformation. ${ }^{6 a}$ All in all, one of the major issues of the reductive olefin coupling, besides alkylations, pericyclic reactions, Michael additions, cross-couplings and radical cyclizations, is the powerful potential for generating 
all-carbon quaternary centers, which is still a challenging motif in total synthesis. An important example is the generation of quaternary centers at the D-ring of steroids, in particular in proximity to existing quaternary centers (see compound 13, Scheme 2). ${ }^{6 a}$ In 2016, Shenvi and co-workers ${ }^{7}$ published the use of ( $\left.i \mathrm{PrO}\right) \mathrm{SiPhH}_{2}$ as an exceptionally mild reductant for metal-catalyzed HATs, which allowed HAT-initiated reactions to be carried out at lower temperatures compared to those used in Baran's protocol., 6

The scope of acceptor molecules was broadened by the use of preformed sulfonyl hydrazones. This protocol now allows the formal incorporation of methyl groups. After radical addition, reductive cleavage of the sulfonyl hydrazine residue leads to the corresponding hydromethylation product 17 (Scheme 3, a). ${ }^{8}$ Using this protocol, Baran was able to transform citronellol (21) into compound 22 in a single step (Scheme 3, c). ${ }^{8}$ Moreover, activity toward the hydroamination of olefins using nitroarenes 18 have been described by the Baran group, with particular dedication to functional group tolerance (Scheme $3, \mathrm{~b}$ ). ${ }^{9} \mathrm{~A}$ representative example is the synthesis of building block $\mathbf{2 5}$, which is useful for applications in medicinal chemistry (Scheme 3, c). ${ }^{6 c}$ Furthermore, Minisci reactions of different substituted heteroarenes $\mathbf{2 6}$ and olefins $\mathbf{2 7}$ show the power and chemoselectivity of these HAT conditions. ${ }^{6 c}$ In contrast to previously reported HAT conditions, ${ }^{6}$ additional Lewis acid activation is required to obtain Minisci products 28 in moderate to good yields (Scheme 3, d). ${ }^{6 c}$ Among the different Lewis acids tested, $\mathrm{BF}_{3}$ proved to provide the highest yields. In this context, Baran and co-workers described the use of pyridine and quinoline $\mathrm{N}$-oxides $\mathbf{2 9}$ in combination with additional Lewis acids as being more effective in HAT-based Minisci reactions (Scheme 3, e). ${ }^{6 c}$

The field of HAT-initiated transformations has been broadened in the recent past. In 2016, Cui and co-workers published an iron-triggered isomerization of $\alpha, \alpha$-diarylallylic alcohols 32 to obtain $\alpha$-aryl ketones 33 in excellent yields (Scheme $4, \mathrm{a}){ }^{10}$ The reaction proceeds via 1,2-migration of an aryl radical and subsequent single-electron-initiated oxidation. However, the choice of suitable reaction partners for HAT-driven processes is certainly not limited to intramolecular olefins, heteroatom-substituted alkenes, Michael acceptors, heteroarenes, nitroarenes and sulfonyl hydrazones. The intramolecular addition of nucleophilic radicals to carbonyl groups of any kind has been studied extensively over the years. ${ }^{11}$ The use of ketones as acceptors in radical reactions is limited due to its reversibility, which is shown in rate studies that provide slower ring closure of nucleophilic radicals to ketones than the corresponding ring opening of alkoxy radical counterparts. ${ }^{11}$ This pathway is well-known as the Beckwith-Dowd ring expansion. ${ }^{11,12}$ Yet, in 2018, the group of Bonjoch and Bradshaw reported on the intramolecular additions of HAT-obtained radicals onto ketone $\mathbf{3 4}$ and provided a number of examples in good (a) Hydromethylation of unactivated olefins (Baran 2015)

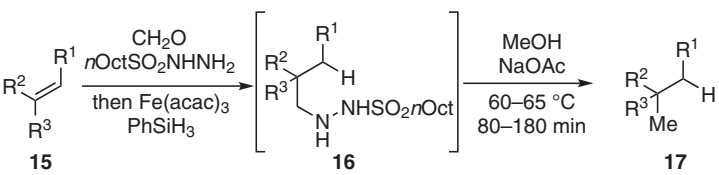

(b) Olefin hydroamination with nitroarenes (Baran 2015)

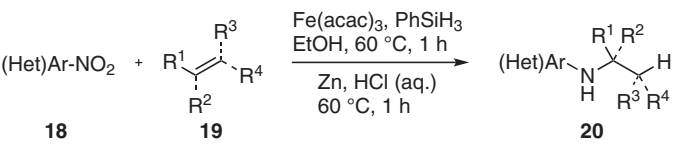

(c) Synthetic examples (Baran 2015)

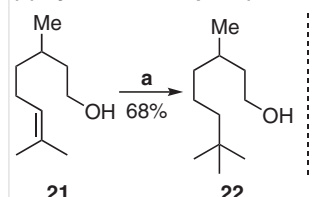

21

22

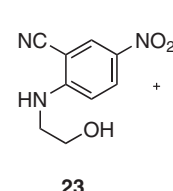

23

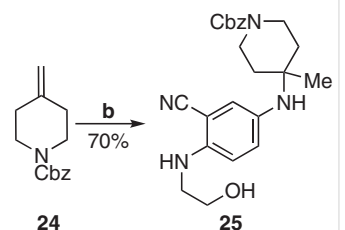

(d) Olefin-based Minisci reactions (Baran 2017)

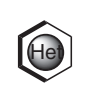

26

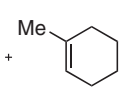

27

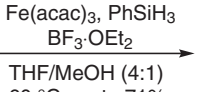

$60{ }^{\circ} \mathrm{C}$, up to $71 \%$

28

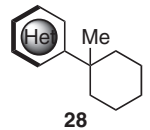

aran 2017)

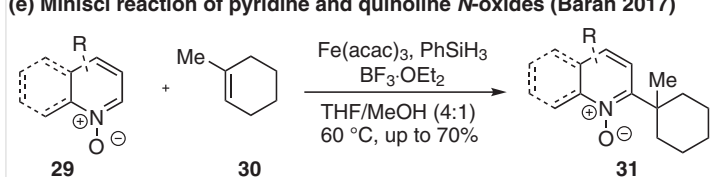

29 30 31

Scheme 3 (a) Hydromethylation, ${ }^{8}$ (b) olefin hydroamination using nitroarenes, ${ }^{9}$ (c) examples of synthetic relevance, ${ }^{8,9}$ (d) olefin-based Minisci reactions, ${ }^{6 c}$ and (e) Minisci reactions of pyridine and quinoline $\mathrm{N}$-oxides ${ }^{6 \mathrm{c}}$ by Baran and co-workers (2015). (i) $\mathrm{CH}_{2} \mathrm{O}, \mathrm{nOctSO}{ }_{2} \mathrm{NHNH}_{2}$, then $\mathrm{Fe}(\mathrm{acac})_{3}, \mathrm{PhSiH}_{3}$ followed by $\mathrm{MeOH}, \mathrm{NaOAc}, 60^{\circ} \mathrm{C}, 2 \mathrm{~h}$; (ii) $\mathrm{Fe}(\mathrm{acac})_{3}, \mathrm{PhSiH}_{3}, \mathrm{EtOH}, 60^{\circ} \mathrm{C}, 1 \mathrm{~h}$, then $\mathrm{Zn}, \mathrm{HCl}(\mathrm{aq}), 60^{\circ} \mathrm{C}, 1 \mathrm{~h}$.

to very good yields (e.g., 35 , Scheme 4, b)..$^{12}$ The radical cyclization of alkene-tethered ketone $\mathbf{3 4}$ provides stable tricyclic alcohol 35. Competition experiments on this reaction pathway in the presence of methyl vinyl ketone show the predominance of the intramolecular cyclization onto the carbonyl group by comparison to the intermolecular reductive olefin coupling with Michael acceptors (Scheme 4, c).., 12

In 2015, Pronin and co-workers published an approach for the construction of the tricyclic framework of paxilline indole diterpenes 39. The key step was a radical-polar crossover polycyclization initiated by $\mathrm{Fe}(\mathrm{acac})_{3}$ and Shenvi's $^{7}(i \mathrm{PrO}) \mathrm{SiPhH}_{2}$, followed by an aldol addition of the in situ formed iron enolate (Scheme $5, a) \cdot{ }^{13}$ Furthermore, this strategy was used to obtain intermediate $\mathbf{4 1}$ to accomplish the total synthesis of emindole SB (Scheme $5, b$ ). ${ }^{13}$

For the construction of the trans-decalin unit 43 of hispidanin A, the Liu group also used Baran's HAT-mediated radical polyene-like cyclization strategy (Scheme $5, \mathrm{c}) \cdot{ }^{14}$ In 
(a) Isomerization of diarylallylic alcohols to $\alpha$-aryl aryl ketones (Cui 2016)

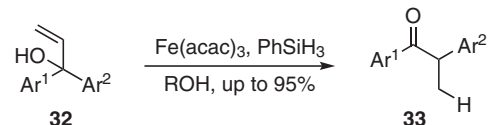

(b) Cyclization of alkene-tethered ketones (Bradshaw and Bonjoch 2018)

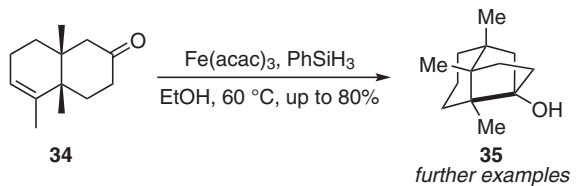

competition experiment: inter- vs. intramolecular (Bradshaw and Bonjoch 2018)

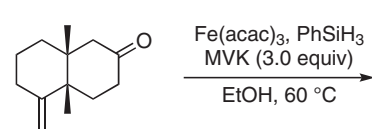

36

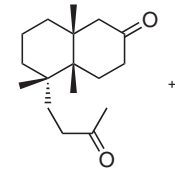

$37(23 \%)$

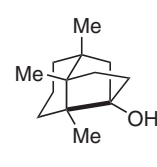

$35(67 \%)$
Scheme 4 (a) Cui's ${ }^{10}$ protocol for the isomerization of diarylallylic alcohols, and (b) Bradshaw and Bonjoch's ${ }^{12}$ radical cyclization of alkenetethered ketones; MVK = methyl vinyl ketone

2015, Carreira and co-workers published the HAT-initiated construction of the core of ( \pm )-hippolachnin A 45 using analogous conditions (Scheme 5, d)..$^{6,15}$

\section{Oxidations and Radical Transformations}

In addition to HAT-initiated reactions, Fe(acac) $)_{3}$ appears in different types of radical-driven synthetic transformations. For decades, the combination of $\mathrm{Fe}(\mathrm{acac})_{3}$ and oxidizing agents (such as dioxygen, hydrogen peroxide and organo hydroperoxides) is known to be able to oxidatively functionalize benzylic and allylic positions, ${ }^{1}$ as well as aromatic systems and conjugated alkenes. ${ }^{16-19}$ From a historical point of view, it is pertinent to mention the first experiments using $\mathrm{Fe}(\mathrm{acac})_{3}$ for the oxidation of cholesterol (46) by Kimura and co-workers in 1973 (Scheme 6, a). ${ }^{16}$ In combination with hydrogen peroxide, the iron-catalyzed oxidation effected selective $\beta$-epoxidation of cholesterol (46) in $68 \%$ yield. This reaction has been investigated to provide a model reaction for biological oxofunctionalizations of steroid skeletons. ${ }^{16}$ Moreover, extensive studies toward biological oxidations of liposomal cholesterol (46) have been described by Kimura and co-workers in $1982^{19}$ and in $1983^{18}$ using $\mathrm{Fe}(\mathrm{acac})_{3}$ as the iron catalyst in the presence of either egg lecithin or unsaturated long-chain fatty acids such as oleic acid (Scheme 6). Oxidation mixtures tend to give compositions of various oxidized products 47-53 with overall moderate to decent conversions (Scheme 6, b and c). ${ }^{18,19}$

(a) Approach to the tricyclic core of paxilline indole diterpenes (Pronin 2015)
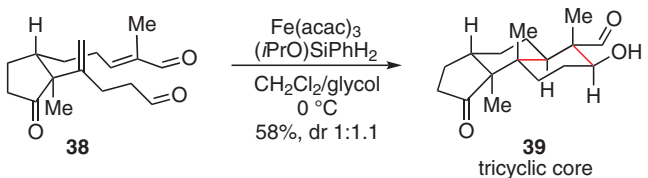

(b) HAT step from enindole SB synthesis (Pronin 2015)

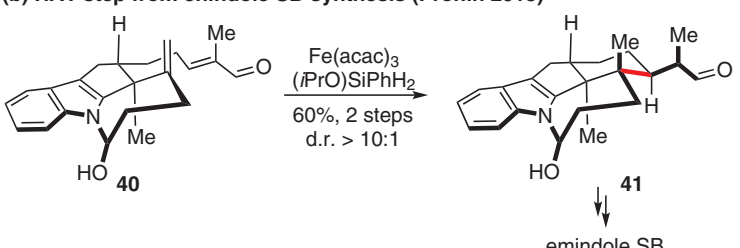

(c) HAT step from hispidanin A synthesis (Liu 2017)

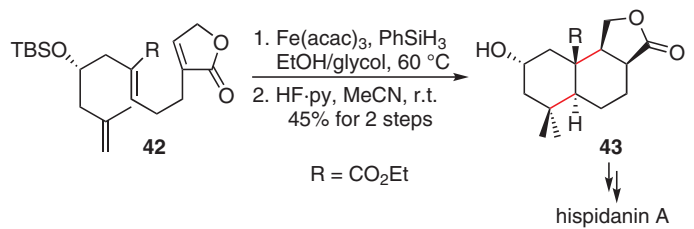

(d) HAT step toward ( \pm )-hippolachnin A synthesis (Carreira 2015)

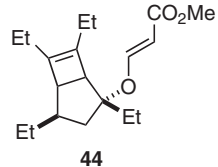

44

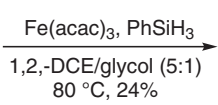
$80{ }^{\circ} \mathrm{C}, 24 \%$<smiles>CCC1CC2(CC)OC(CC(C)C)CC1(CC)C2C</smiles>

$\downarrow$

( \pm )-hippolachnin A

Scheme 5 (a) Pronin's HAT for the construction of paxilline indole diterpene cores, ${ }^{13}$ (b) the synthesis of emindole SB, ${ }^{13}$ (c) the HAT step of Liu's hispidanin A synthesis, ${ }^{14}$ and (d) construction of the core of $( \pm$ )hippolachnin A by Carreira ${ }^{15}$

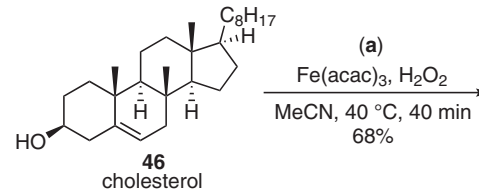

(b) (c)

\begin{tabular}{r|r}
$\mathrm{Fe}(\mathrm{acac})_{3}, \mathrm{O}_{2}$ & $\mathrm{Fe}(\mathrm{acac})_{3}$ \\
egg lecithin & oleic acid
\end{tabular}

egg lecithin oleic acid hydroperoxide

$\mathrm{PhH}, 60^{\circ} \mathrm{C} \mathrm{PhH}, 60^{\circ} \mathrm{C}, \mathrm{Ar}$ $\mathrm{R}=\mathrm{H} \quad \mathrm{R}=\mathrm{Ac}$ $\mathrm{L}=$ oleic acid

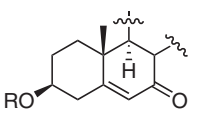

48 (b) $23 \%$ (c) $6 \%$<smiles>CC1C(O)C=C2C[C@@H](O)CC[C@]2(C)C1(C)C</smiles>

51 (b) $5 \%$

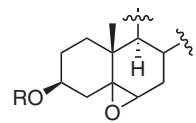

47 (b) $3 \%$ (c) $34 \%$<smiles>[R9][C@H]1CC[C@@]2(C)[C@H](C)[C@H](C)C[C@H](O)[C@]2(O)C1</smiles>

52 (b) $18 \%$

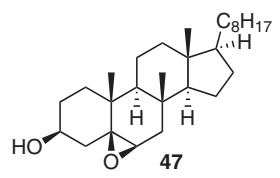<smiles>CC1CCCC2(C)CCC(O)CC2=CC1O</smiles>

49 (c) $4 \%$<smiles>CC1C(O)C=C2CC([O])CCC2(C)C1C</smiles>

50 (b) $13 \%$ (c) $6 \%$

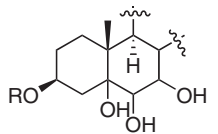

53 (b) $12 \%$
Scheme 6 (a) Historical overview of $\beta$-epoxidation of cholesterol by Kimura $1973,{ }^{16}$ and autoxidations of cholesterol (b) by Kimura $1983^{18}$ and $(c)$ in $1982^{19}$ 
However, in this work by Kimura, ${ }^{16} \mathrm{Fe}(\mathrm{acac})_{3}$ in the presence of oxidizing agents was the origin for further ironbased oxidations in a wide variety of substrates. More recently, several methods for the oxidation of benzylic alcohols and benzylic positions have been published (Scheme 7). In 1996, Nobile, Lopez and co-workers demonstrated the aerobic oxidation of $\alpha$-hydroxy aryl ketones $\mathbf{5 4}$ to obtain symmetrically substituted 1,2-diketones $\mathbf{5 5}$ in good to excellent yields using catalytic amounts of $\mathrm{Fe}(\mathrm{acac})_{3}$, dioxygen and a sacrificial aldehyde, albeit the substrate scope was limited to aromatic substituents (Scheme 7, a). ${ }^{20}$ Further dehydrogenations with catalytic amounts of $\mathrm{Fe}(\mathrm{acac})_{3}$ in the presence of potassium carbonate and 1,10-phenanthroline to obtain aryl ketones $\mathbf{5 7}$ were performed by the Hong group in 2014 (Scheme 7, b). ${ }^{21}$ The advantage of this methodology is the absence of sacrificial reagents for hydrogen acceptance. However, the oxidation only proceed with secondary alcohols in benzylic positions (Scheme 7). ${ }^{21} \mathrm{~A}$ similar type of reaction is the introduction of organo peroxides at benzylic, allylic or propargylic ether positions. In 2012, Urabe reported the synthesis of tert-butyl peroxyacetals $\mathbf{5 8}$ starting from the corresponding ethers $\mathbf{5 8}$ by applying $\mathrm{Fe}(\mathrm{acac})_{3}$ in catalytic amounts with an excess of tert-butyl hydroperoxide in toluene (Scheme 7, c). ${ }^{22}$ The corresponding peroxyacetals 59 (further examples: 61, 63, 65, 67 and others ${ }^{22}$ were obtained in excellent yields. In 1999, Blanco and co-workers described an oxidative rearrangement of bicyclo[n.1.0]alkan-1-ols $\mathbf{6 8}$ with a reagent mixture of catalytic amounts of $\mathrm{Fe}(\mathrm{acac})_{3}$, silica gel, and dioxygen under irradiation (100 W domestic light bulb) to obtain the corresponding $\beta$-hydroperoxy cyclohexanones 69 in decent yields (Scheme 7, d). ${ }^{23}$ By prolonging the reaction time from three to 36 hours, in the case of cyclopropane 70, a subsequent ring closure yielding the corresponding peroxyacetal 71 was observed (Scheme 7, d).23

Furthermore, Pan and co-workers published an alkenylation of cyclic ethers $\mathbf{7 3}$ using $\mathrm{Fe}(\mathrm{acac})_{3}$ and DTBP as a radical starter. This reaction proceeds via a radical decarboxylative $\mathrm{sp}^{2}-\mathrm{sp}^{3}$ coupling and afforded alkenylated dioxanes 74, pyrans and tetrahydrofurans in good yields (Scheme 8, a). ${ }^{24}$ The same group reported the use of cycloalkanes, e.g., cyclopentane, cyclohexane (76), cycloheptane etc., for the decarboxylative alkenylation and obtained the corresponding alkenylated cycloalkanes $\mathbf{7 7}$ in moderate to very good yields (Scheme 8, b). ${ }^{25}$

In 2016, Patel and co-workers reported the selective functionalization of the $\mathrm{C}-3$ position in flavones $\mathbf{7 8}$ by using catalytic amounts of $\mathrm{Fe}(\mathrm{acac})_{3}$, potassium persulfate, DABCO and either tert-butyl peroxybenzoate for the introduction (a) Aerobic oxidation of $\alpha$-hydroxy aryl ketones (Nobile and Lopez 1996)

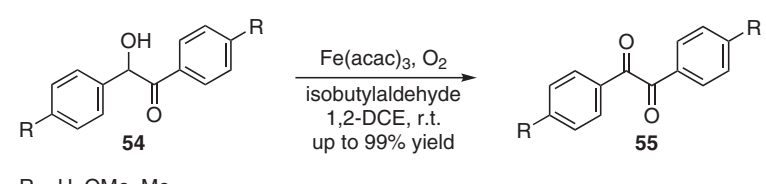

$\mathrm{R}=\mathrm{H}, \mathrm{OMe}, \mathrm{Me}$

(b) Acceptorless dehydrogenation of secondary benzylic alcohols (Hong, 2014)

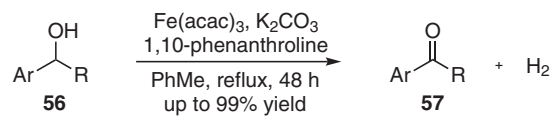

$$
\begin{aligned}
& \mathrm{R}=\mathrm{alkyl}, \mathrm{aryl}
\end{aligned}
$$

(c) Synthesis of tert-butyl peroxyacetals from benzyl, allyl and propargyl ethers (Urabe 2012)
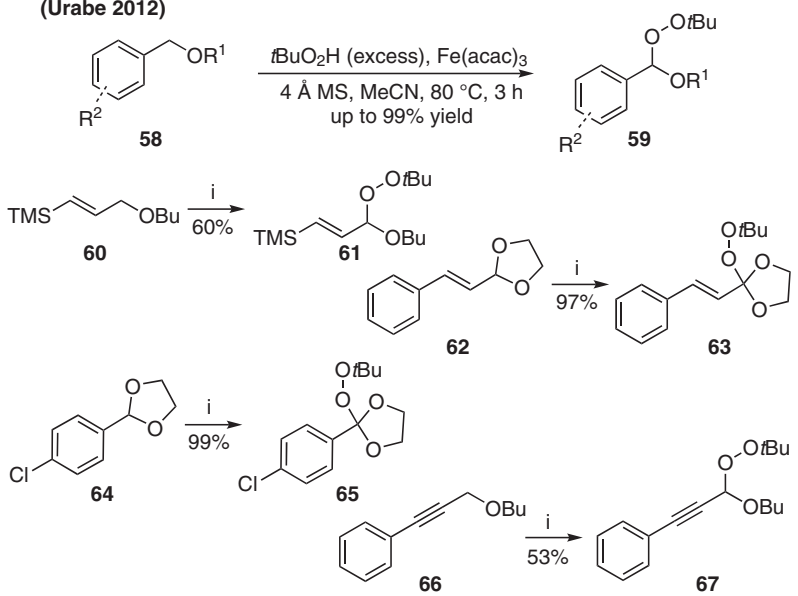

(d) Oxidative rearrangement of bicyclo[n.1.0]alkan-1-ols (Blanco, 1999)

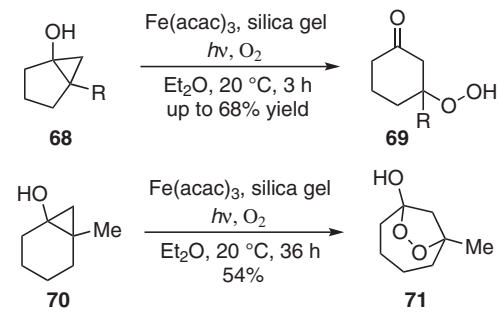

Scheme 7 (a) Aerobic oxidation of $\alpha$-hydroxy aryl ketones by Nobile and Lopez, ${ }^{20}$ (b) dehydrogenation of secondary benzylic alcohols by Hong, ${ }^{21}$ (c) synthesis of several tert-butyl peroxyacetals by Urabe, ${ }^{22}$ and (d) oxidative rearrangement of bicycloalkanols in the presence of oxygen by Blanco. ${ }^{22}$ (i) TBHP, Fe(acac) $)_{3}, 4 \AA \mathrm{MS}, \mathrm{MeCN}, 80^{\circ} \mathrm{C}, 3 \mathrm{~h}$.

of a single methyl group, or cycloalkynes or formamides for the introduction of a cycloalkyl residue or formyl group at elevated temperatures (Scheme 8, c). ${ }^{26}$

\section{Synthesis and Use of Alkynes and Allenes}

Numerous applications of iron in the context of alkyne chemistry varying from alkyne synthesis to selective addition and annulations have been published in the recent 
(a) Alkenylation of cyclic ethers (Pan, 2013)

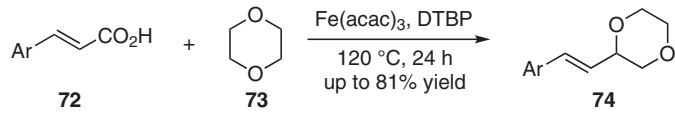

(b) Alkenylation of cycloalkanes (Pan, 2013)

$$
\underset{75}{\mathrm{Ar}} \mathrm{CO}_{2} \mathrm{H}+\bigodot_{76} \frac{\mathrm{Fe}(\mathrm{acac})_{3}, \mathrm{DTBP}}{\begin{array}{c}
120^{\circ} \mathrm{C}, 24 \mathrm{~h} \\
\text { up to } 91 \% \text { yield }
\end{array}}
$$

(c) C-3 Functionalization of flavones (Patel, 2016)

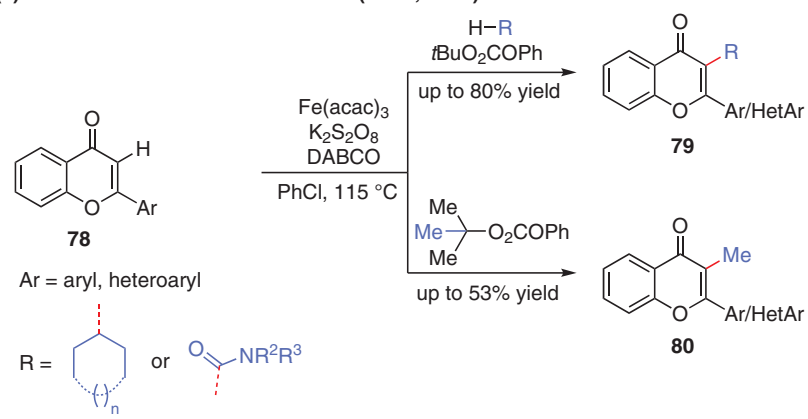

Scheme 8 (a) Alkenylation of cyclic ethers, ${ }^{24}$ (b) alkenylation of cycloalkanes by Pan, ${ }^{25}$ and (c) peroxide-mediated C-3-functionalization of flavones; ${ }^{26}$ DTBP = di-tert-butyl peroxide

past. ${ }^{1,2}$ In 2015, Fürstner reported a new method for the synthesis of non-terminal alkynes $\mathbf{8 3}$ starting from lactones 81 (Scheme 9). ${ }^{27}$ The lactone was converted into the corresponding 1,1'-dichloro olefin $\mathbf{8 2}$ and subsequently treated with $\mathrm{Fe}(\mathrm{acac})_{3}$ and methyllithium. The method provides a broad scope of methylated alkynes $\mathbf{8 3}$ in yields of up to $95 \%$ (Scheme 9, a). This strategy was applied to the synthesis of fragment $\mathbf{8 6}$ in Fürstner's total synthesis of tulearins A and $\mathrm{C}$ (Scheme 9, b). ${ }^{27}$

(a) Synthesis of non-terminal alkynes (Fürstner 2015)

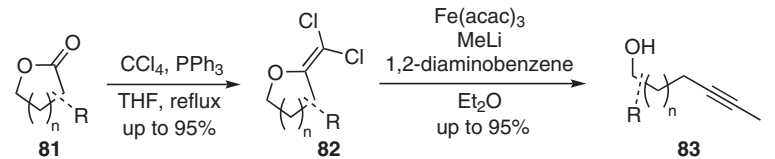

(b) Part of the tulearin A and C synthesis (Fürstner 2015)

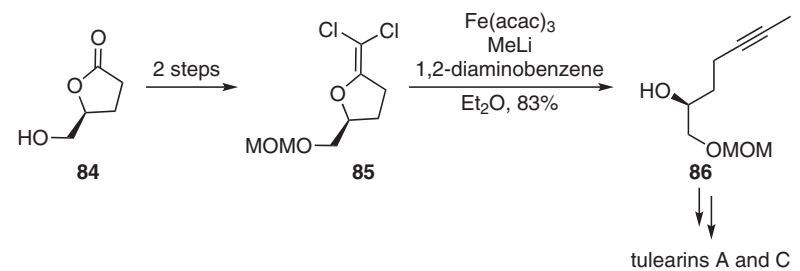

Scheme 9 (a) Fürstner's synthesis of non-terminal alkynes, and (b) application to the synthesis of tulearin ${ }^{27}$

When it comes to the use of alkynes as starting materials, Bäckvall's group published the synthesis of substituted allenes $\mathbf{8 8}$ starting from propargylic acetates $\mathbf{8 7}$ (Scheme
10, a). ${ }^{28}$ Bäckvall and Kessler utilized a large substrate scope obtaining good to excellent yields of the allene products. The reaction proceeds via and an iron-catalyzed cross-coupling mechanism. Earlier, Fürstner introduced examples for the synthesis of substituted allenes $\mathbf{9 0}$ starting either from propargylic epoxides $\mathbf{8 9}^{29}$ or propargylic cyclopropanes $\mathbf{9 1}^{30}$ bearing a geminal diester on the cyclopropane core (Scheme 10, b and c). A convenient example from natural product total synthesis is Fürstner's $\mathrm{Fe}(\mathrm{acac})_{3}$-catalyzed method to convert propargylic epoxide 93 into the corresponding trisubstituted allene 94 in $62 \%$ yield and good diastereoselectivity en route toward amphidinolide $\mathrm{Y}$ (Scheme 10, d). ${ }^{31}$

(a) Synthesis of substituted allenes (Bäckvall 2016)

$$
\mathrm{R}^{3}={\underset{\mathbf{8 7}}{\mathrm{OAc}}}_{\mathrm{R}^{2}}^{\mathrm{R}^{1}} \frac{\begin{array}{c}
\mathrm{Et}_{2} \mathrm{O},-20^{\circ} \mathrm{C}, 35 \mathrm{~min} \\
\text { up to } 99 \% \text { yield }
\end{array}}{\mathrm{R}^{4}}=\overbrace{\mathbf{8 8}}^{\mathrm{R}^{2}}
$$

(b) Synthesis of substituted allenes bearing an allylic alcohol (Fürstner 2003)

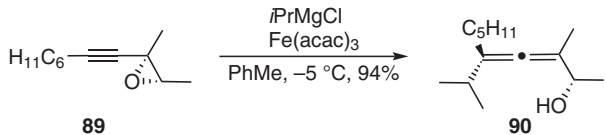

(c) Synthesis of 1,2-disubstituted allenes (Fürstner 2009)

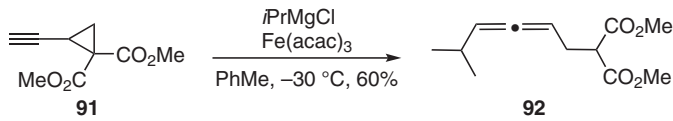

(d) A step toward the total synthesis of amphidinolide Y (Fürstner, 2006)

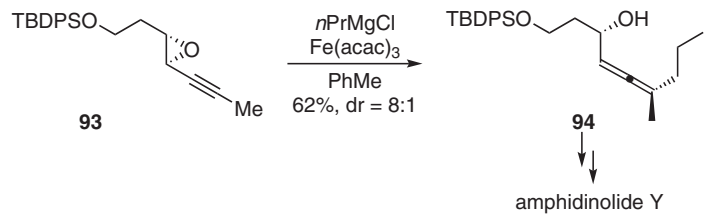

Scheme 10 (a) Synthesis of substituted allenes by Bäckvall, ${ }^{28}$ (b) and (c) by Fürstner, ${ }^{29,30}$ and (d) an excerpt from the total synthesis of amiphidinolide $\mathrm{Y}^{31}$

A broader field in the use of $\mathrm{Fe}(\mathrm{acac})_{3}$ in alkyne chemistry is the benzannulation of aryl compounds. In 2011, Nakamura reported a [4+2] benzannulation between biaryl or 2-alkenylphenyl Grignard reagents 96 and alkynes 95 for the synthesis of polyaromatic compounds $\mathbf{9 7}$ (Scheme 11, a). ${ }^{32}$ The scope is limited to aryl Grignard reagents but a variety of variations on alkynes $\mathbf{9 5}$ are possible. Optimized reaction conditions use catalytic amounts of $\mathrm{Fe}(\mathrm{acac})_{3}$ and dtbpy as the ligand in the presence of 1,2-dichloro-iso-butane as oxidant, which was required to prevent partial polymerization of the alkyne. The use of aminoquinoline carboxamides 98 established the possibility to perform directed iron-catalyzed $\mathrm{C}-\mathrm{H}$ bond activation, which was reported by Nakamura for the preparation of disubstituted indenones 99 in moderate to very good yields (Scheme 11, b). ${ }^{33}$ 
(a) [4+2] Benzannulation between aryl Grignard reagents and alkynes (Nakamura 2011)
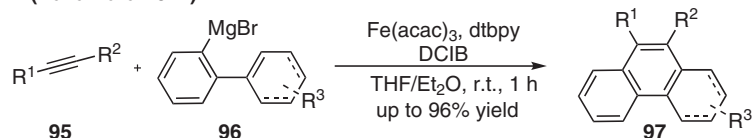

$\mathrm{R}^{1}, \mathrm{R}^{2}=$ aryl, alkenyl,

$\mathrm{R}^{3}=\mathrm{Me}$

(b) Synthesis of indenones (Nakamura 2018)

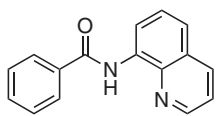

98

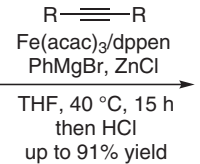

$\mathrm{R}=$ alkyl, aryl

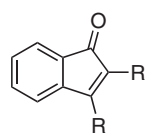

99
Scheme 11 (a) Nakamura's [4+2] benzannulation ${ }^{32}$ between aryl Grignards and alkynes, and (b) synthesis of indenones; ${ }^{33} \mathrm{dtbpy}=4,4^{\prime}$-ditert-butyl-2,2'-bipyridyl, DCIB = 1,2-dichloro-iso-butane, dppen = 1,2bis(diphenylphosphino)ethylene

Carbometalations ${ }^{34}$ of alkynes represent a highly stereo and regioselective tool for the synthesis of higher functionalized and tetrasubstituted olefins. Examples using catalytic amounts of $\mathrm{Fe}(\mathrm{acac})_{3}$ for syn-carbometalations are discussed below (Scheme 12). In 2001, Hosomi and co-workers published a carbolithiation of internal alkynes $\mathbf{1 0 0}$ for the synthesis of higher substituted olefins $\mathbf{1 0 1}$ by using $n$ butyllithium and $\mathrm{Fe}(\mathrm{acac})_{3}$ (Scheme 12, a). ${ }^{35}$ The vinyl lithium intermediate could be trapped by electrophiles of any kind $\left(\mathrm{H}^{+}, \mathrm{D}^{+}, \mathrm{XSiR}_{3}\right.$, aldehydes, ketones), which makes this method applicable for a variety of different structures. Further variations of carbomagnesiations of alkynes were reported by Hayashi using catalytic amounts of $\mathrm{Fe}(\mathrm{acac})_{3}$, either with $\mathrm{CuBr}^{36}$ or a N-heterocyclic carbene ligand. ${ }^{37}$ Using these conditions, Hayashi was able to obtain trisubstituted olefins 103 and $\mathbf{1 0 5}$ in very good yields and $E: Z$ ratios (Scheme 12, b and c). In 2007, Ma and co-workers reported the regio and stereoselective addition of Grignard reagents to 2,3-allenoates $\mathbf{1 0 6}$ for the synthesis of $\beta, \gamma$-unsaturated trisubstituted olefins 107 (Scheme 12, d). ${ }^{38}$ Carbometalations of propargylic and homopropargylic alcohols $\mathbf{1 0 8}$ with Grignard reagents have been reported by Ready with broad substrate scope and the possibility of trapping vinylmagnesium compounds with different electrophiles (e.g., $\mathrm{H}^{+}, \mathrm{D}^{+}, \mathrm{ZnCl}_{2} / \mathrm{NBS}$, aldehydes, CuCN/2LiCl/allyl bromide) (Scheme 12, e) ${ }^{39}$ This carbomagnesiation procedure was applied by the Ma group for an alkyne methylation to obtain intermediate $\mathbf{1 1 1}$ for the total synthesis of leucosceptroids A and B (Scheme 12, f).40 (a) Regio and stereoselective carbolithiation of alkynes (Hosomi, 2001)

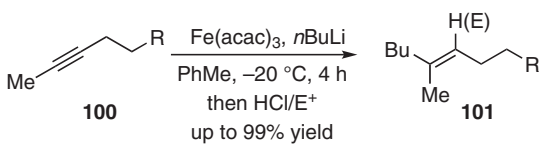

(b) Arylmagnesiation of alkynes (Hayashi 2005)

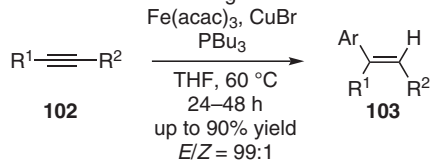

$$
\begin{aligned}
& \mathrm{R}^{1}=\mathrm{H} \text {, alkyl; } \mathrm{R}^{2}=\text { alkyl, aryl, TMS }
\end{aligned}
$$

(c) Arylmagnesiation of alkynes in the presence of a NHC ligand (Hayashi 2006)
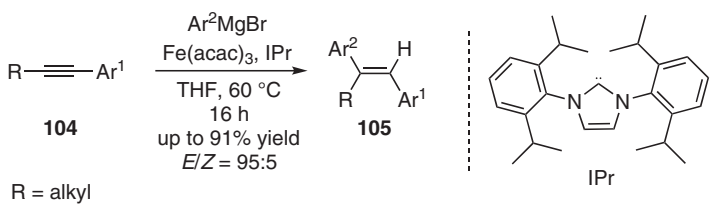

(d) Regio and stereoselective addition to 2,3-allenoates (Ma 2007)

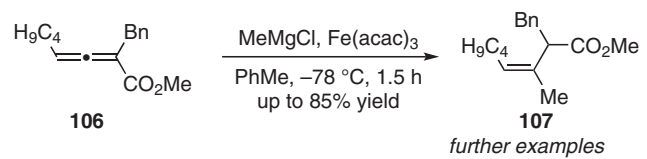

(e) Carbometalation of propargylic and homopropargylic alcohols (Ready 2006)

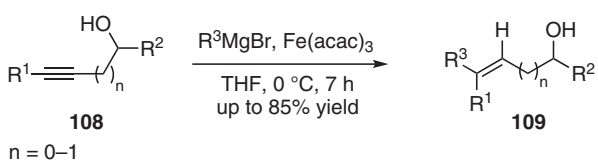

(f) A step of leucosceptroid A and B syntheses (Ma, 2015)

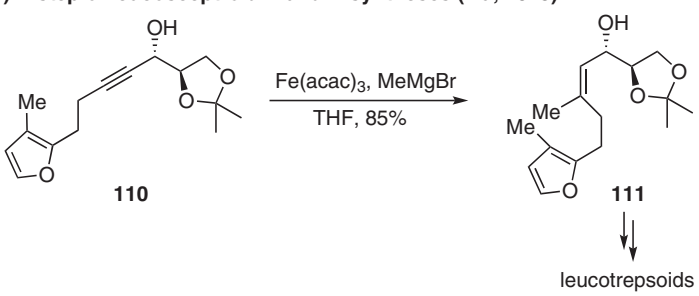

Scheme 12 (a) Hosomi's regio- and stereoselective carbolithiation of alkynes, ${ }^{35}$ (b) and (c) arylmagnesiation of alkynes by Hayashi, ${ }^{36,37}$ (d) regio and stereoselective addition of 2,3-allenoates with Grignard reagents by $\mathrm{Ma},{ }^{38}$ (e) Ready's carbometalation of propargylic and homopropargylic alcohols, ${ }^{39}$ and (f) application in Ma's total synthesis of leucosceptroids $A$ and $B^{40}$

\section{Cross-Couplings and Cycloisomerizations}

Cross-coupling reactions have become irreplaceable tools for the synthesis of $\mathrm{C}-\mathrm{C}$ bonds at $\mathrm{sp}, \mathrm{sp}^{2}$ and $\mathrm{sp}^{3}$ hybridized carbon atoms bearing a wide range of residues on both sides of the reaction partners. One of the first described approaches using palladium or nickel as metals for this kind of transformation was the coupling of Grignard reagents with aryl or vinyl halides by Kumada and co-workers. ${ }^{41}$ As far back as 1941 , the first Fe-catalyzed cross-cou- 
pling was reported by Fields and Kharash, the value of which only became apparent a few decades later. ${ }^{42}$ The substrate scope of Fe-catalyzed cross-coupling reactions is extremely broad since aliphatic substrates are also compatible with this method. Therefore, it is an even more powerful C$\mathrm{C}$ bond-forming reaction compared to the corresponding Pd-catalyzed transformations (Scheme 13).

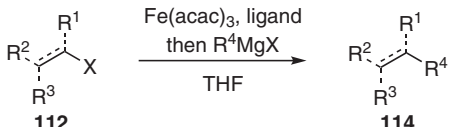

Scheme 13 General procedure for $\mathrm{Fe}(\mathrm{acac})_{3}$-catalyzed cross-couplings

Oxidations states ranging from $\mathrm{Fe}(-\mathrm{II})$ up to $\mathrm{Fe}(\mathrm{III})$ species are proposed to be involved in the catalytic cycle depending on the type of cross-coupling. In most cases the initial step is the in situ reduction of $\mathrm{Fe}(\mathrm{acac})_{3}$ to a low valent iron species. The different mechanisms are reviewed elsewhere. ${ }^{43,44}$ Even though reactive intermediates are difficult to characterize experimentally, the formation of the intermediary ate-complexes was at least confirmed by the group of Koszinowski who found evidence for $\mathrm{Fe}(\mathrm{III}), \mathrm{Fe}(\mathrm{II})$ and $\mathrm{Fe}(\mathrm{I})$ species via electrospray ionization mass spectrometry. Further investigations suggested that product formation occurred from a $\left[\mathrm{Ph}_{3} \mathrm{Fe}^{\mathrm{III}} i \mathrm{Pr}\right]^{-}$complex (in the case of a $\mathrm{PhMgBr}$ to $i \mathrm{PrCl}$ coupling) to give $\left[\mathrm{Ph}_{2} \mathrm{Fe}(\mathrm{I})\right]^{-}$and $\mathrm{Ph} i \mathrm{Pr}$ as the desired product. ${ }^{45}$

\subsection{Fe-Catalyzed $s p^{2}-s p^{2}$ Cross-Coupling Reactions}

Transition-metal-catalyzed $\mathrm{sp}^{2}-\mathrm{sp}^{2}$ cross-coupling reactions were first reported by Julia and co-workers. They investigated the reaction between tert-butyl sulfones with phenylmagnesium bromide using different metal acetoacetonates (Scheme 14, a ). ${ }^{46 a}$ In contrast, Knochel and co-workers used either aromatic Grignard reagents or the corresponding cuprates in cross-coupling reactions with vinyl halides or sulfonyl enols. These conditions were even compatible with intramolecular ester moieties on the organometallic reagent (Scheme 14, a). ${ }^{46 b, c}$ On the other hand, the use of phenyl thioethers only allows minor substitution pattern variability on the aromatic system (Scheme 14, a). ${ }^{46 \mathrm{~d}}$ The first homo-coupling of two halogenated aromatic compounds via in situ formation of the Grignard reagent gave access to dimeric compounds $\mathbf{1 1 8}$ and was also applicable to aliphatic halides (Scheme 14, b). ${ }^{47}$ Since there is a large variety of $\mathrm{Fe}(\mathrm{acac})_{3}$-catalyzed cross-couplings in synthetic chemistry, only selected examples will be mentioned briefly. The group of Li used a $\mathrm{sp}^{2}-\mathrm{sp}^{2}$ cross-coupling between 2,4- $\mathrm{F}_{2} \mathrm{C}_{6} \mathrm{H}_{4} \mathrm{MgBr}$ and vinyl chloride 119 to construct the carbon skeleton of the eastern fragment 120 of posaconazole in $76 \%$ yield (Scheme $14, \mathrm{c}) .^{48}$ (a) $\mathrm{sp}^{2}-\mathrm{sp}^{2}$ cross-couplings (Julia 1982 i.a.)

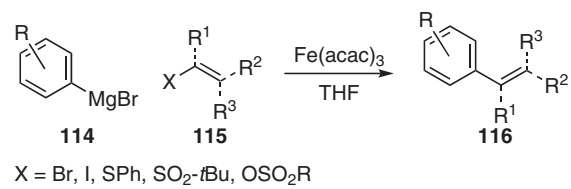

(b) $\mathrm{sp}^{2}-\mathrm{sp}^{2}$ homocoupling (Pei 2006)

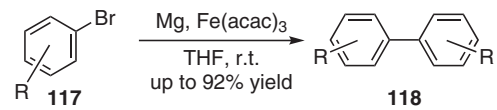

(c) Application to the total synthesis posaconazole (Li 2015)

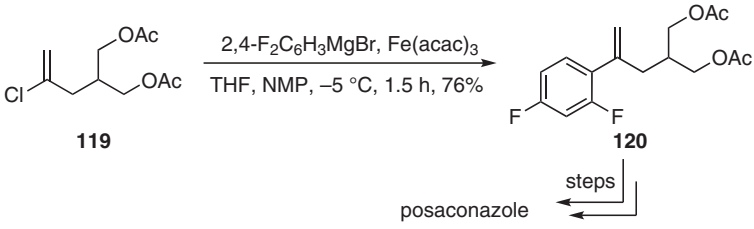

Scheme 14 (a) Fe-catalyzed $s p^{2}-s p^{2}$ cross-couplings of aryl and vinylic substrates, ${ }^{46}$ (b) $\mathrm{sp}^{2}-\mathrm{sp}^{2}$ homo-coupling, ${ }^{47}$ and (c) Fe-catalyzed crosscoupling towards the total synthesis of posaconazole; ${ }^{48} \mathrm{NMP}=\mathrm{N}$-methylpyrrolidine

Sweeney and co-workers were able to establish a tandem Heck-Kumada cross-coupling reaction to construct dihydrofuran 122 in high yield and diastereoselectivity. ${ }^{49}$ The stereochemical outcome can be rationalized by the disfavored steric interactions of the iron residue and the $\mathrm{C}-\mathrm{H}$ bond at the ortho position of the aromatic ring (Scheme 15).

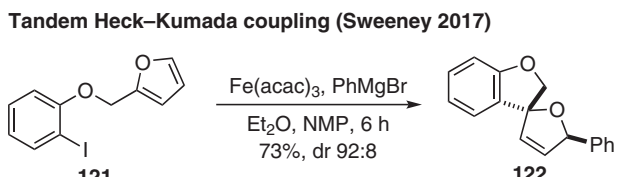

Scheme 15 A tandem Heck-Kumada cross-coupling reported by Sweeney and co-workers ${ }^{49}$

\subsection{Fe-Catalyzed $s \mathrm{p}^{2}-s \mathrm{p}^{3}$ Cross-Coupling Reactions}

Fe-catalyzed $\mathrm{sp}^{2}-\mathrm{sp}^{3}$ (electrophile-nucleophile) crosscouplings offer the advantage of not undergoing $\beta$-hydride eliminations in contrast to palladium-catalyzed cross-couplings. The use of aliphatic Grignard reagents requires NMP as a co-solvent. It is proposed to be essential for the formation of the $\left[\mathrm{Mg}(\mathrm{NMP})_{6}\right]\left[\mathrm{FeMe}_{3}\right]_{2}$ complex, which is pivotal for high selectivities using aliphatic Grignard reagents. ${ }^{50}$

The cross-coupling of vinyl or aryl electrophiles with aliphatic Grignards tolerates a wide variety of functional groups such as different electron-withdrawing or electrondonating groups on the electrophile. Furthermore, ester moieties are also compatible with these organometallic species. Thus, electrophiles such as $\mathrm{Cl}, \mathrm{Br}$, I, OTs, OTf, SePh, $\mathrm{TePh}$ and $\mathrm{NMe}_{3} \mathrm{OTf}$ can be employed in $\mathrm{Fe}(\mathrm{acac})_{3}$-mediated cross-couplings, delivering the desired products in good to 
high yields and good diastereoselectivities (Scheme 16, a). ${ }^{43 c, 51}$ Furthermore, even more complex substrates exhibiting polyaromatic, bridgehead, allyl amine or vinyl alkynyl motifs are also compatible with this methodology. In particular, tosyl-substituted Michael acceptors such as $\mathbf{1 2 5}$ can be joined to aliphatic residues to give access to highly substituted double bonds with excellent control of the double bond geometries (Scheme 16, b). ${ }^{52}$ Moreover, the use of enol phosphonates 127 was reported by the Habiak and Gagner groups. These substrates can easily be synthesized from the corresponding ketones and are easier to handle on large scale compared to their corresponding triflates. ${ }^{53}$ In continuation of their contribution on these enol phosphonates, the substrate scope could be enlarged to conjugated phosphonate dienes (Scheme $16, \mathrm{c}) .^{53}$ As Fe(acac) ${ }_{3}$-catalyzed cross-couplings tolerate a large variety of functional groups, Marquais and co-workers used manganese instead of Grignard nucleophiles to broaden the substrate scope to ketones (Scheme 16, d). ${ }^{54 a}$ In addition, the tolerance of Grignard reagents to ketones was reported by Cahiez in 2009.54b Besides coupling to carbon residues, $\mathrm{Fe}(\mathrm{acac})_{3}$ and $t \mathrm{BuMgCl}$ can be used for dehalogenation. The proposed mechanism involves hydride transfer from the $t \mathrm{Bu}$ group to the Fe-arene species, which then undergoes reductive elimination (Scheme 16, e). ${ }^{55}$ The application of $\mathrm{Fe}(\mathrm{acac})_{3}$-mediated $\mathrm{sp}^{2}-\mathrm{sp}^{3}$ cross-couplings in total synthesis was, amongst others, ${ }^{1,56}$ demonstrated by the Kirschning group in their total synthesis of noricumazol A. The Fe(acac) $)_{3}$-catalyzed $\mathrm{C}-\mathrm{C}$ bond formation between MOM-protected phenol 134 and alkyl Grignard species 133 gave the core of the eastern fragment 135 in an excellent yield (Scheme 16, f). ${ }^{57}$

\subsection{Fe-Catalyzed $s^{3}-s p^{2}$ Cross-Coupling Reactions}

Fe-catalyzed $\mathrm{sp}^{3}-\mathrm{sp}^{2}$ cross-couplings of aromatic Grignard reagents to primary or secondary electrophiles make use of a large variety of substrates. Cyclic or linear aliphatic starting materials as well as halogenated azetidines deliver good to excellent yields in cross-coupling reactions. ${ }^{58}$ The use of thioethers as electrophiles in cross-coupling reactions has been described by Denmark and co-workers using phenyl and pyridinyl thioethers or sulfones (Scheme 17, a) ${ }^{58 \mathrm{~d}}$ Furthermore, modified Suzuki ${ }^{59}$ cross-coupling reactions have been reported by the Bedford group. ${ }^{60}$ They used $t \mathrm{BuLi}$ to activate the boron species as its ate-complex, followed by Lewis acid activated C-C bond formation (Scheme 17, b). Nakamura and co-workers developed a protocol for the $\mathrm{sp}^{3}-\mathrm{sp}^{2}$ Negishi ${ }^{61 \mathrm{a}}$ coupling with substrates bearing esters or nitriles on the aliphatic side chain (Scheme 17, b). ${ }^{61 \mathrm{~b}}$ Hu's group developed conditions for coupling $\mathrm{CF}_{2} \mathrm{H}$ groups to organozinc or magnesium compounds, while Zhang and co-workers reported a Pd-Fe co-catalyzed coupling of $\mathrm{CF}_{2} \mathrm{H}$ (a) $\mathrm{sp}^{2}-\mathrm{sp}^{2}$ cross-coupling (Krause 2002 i.a.)

$$
\mathrm{X}=\mathrm{Cl}, \mathrm{Br}, \mathrm{I}, \mathrm{OTs} \text {, OTf, SePh, TePh, } \mathrm{NMe}_{3} \mathrm{OTf}
$$

(b) Electron-deficient vinyl tosylates (Tanabe 2010)

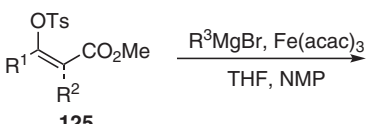

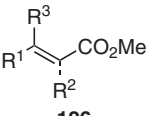

(c) Vinyl phosphonates (Habiak 2008 \& Gager 2008)

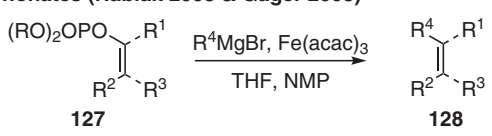

(d) Organo manganese nucleophiles (Marquais 1996)

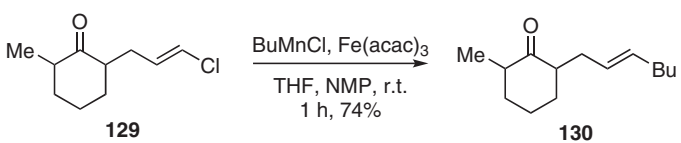

(e) Dehalogenation of aryl halides (von Wangelin 2010)

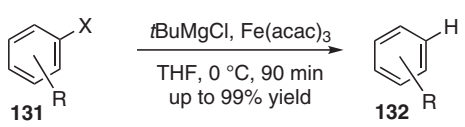

(f) Application to the total synthesis of noricumazol A (Kirschning 2012)

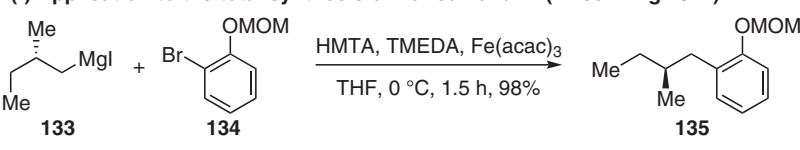

noricumazol A steps

Scheme 16 (a) Fe-catalyzed $\mathrm{sp}^{2}-\mathrm{sp}^{3}$ cross-couplings with different substrates, ${ }^{51}$ (b) cross-couplings on Michael acceptors, ${ }^{52}$ (c) vinyl phosphonate- $\mathrm{sp}^{2}$ cross-coupling, ${ }^{53}(\mathrm{~d})$ an organo manganese nucleophile which tolerates ketones, ${ }^{54}$ (e) dehalogenation of aryl halides, ${ }^{55}$ and ( $f$ ) a $\mathrm{Fe}(\mathrm{acac})_{3}$-catalyzed cross-coupling for the synthesis of the eastern fragment core of noricumazol $A ;{ }^{57}$ HMTA = hexamethylenetetraamine, TMEDA = tetramethylethylenediamine

groups involving a $\mathrm{CF}_{2}$ carbene intermediate (Scheme 17, c) ${ }^{62,63}$ Beginning with benzaldehyde, Leino designed an in situ reduction of a carbonyl group to its corresponding chloride followed by coupling to the second aryl unit (Scheme 17, d). ${ }^{64}$ The introduction of chirality toward the $\mathrm{sp}^{3}$-hybridized C-atom was first accomplished in an $\mathrm{Fe}(\mathrm{acac})_{3}$-mediated cross-coupling by Nakamura in 2015 . $^{43 \mathrm{e}}$ Originating from racemic $\alpha$-chloro ester 148 the enantioenriched coupling product $\mathbf{1 5 1}$ was obtained in an enantiomeric ratio (e.r.) of $87: 13$ and $75 \%$ yield. This transformation was most effective with $\mathrm{R}^{2}$ being a methyl group (Scheme 17, e). Further cleavage of the theptyl ester delivers free acid dexibuprofen (152), which can be co-crystallized with octylamine to enhance the e.r. up to $>99: 1.43 \mathrm{e}$ 
(a) $\mathrm{sp}^{3}-\mathrm{sp}^{2}$ cross-coupling (Moyeux 2007 i.a.)

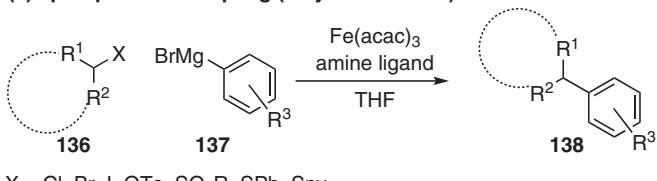

X

(b) Suzuki and Negishi cross-coupling (Bedford 2014, Nakamura 2009)<smiles></smiles>

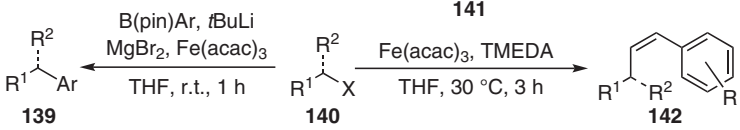

(c) Coupling of $\mathrm{CF}_{2} \mathrm{H}$ groups ( $\mathrm{Hu} 2018$ )

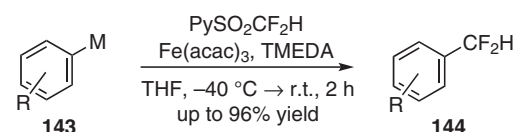

(d) Reductive cross-coupling (Leino 2014)<smiles>CCCC(=O)c1ccccc1</smiles>

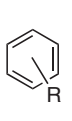

146

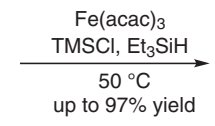

up to $97 \%$ yield

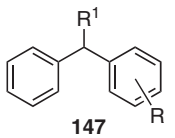

(e) Enantioselective cross-coupling reactions and synthesis of dexibuprofen (Nakamura 2015)

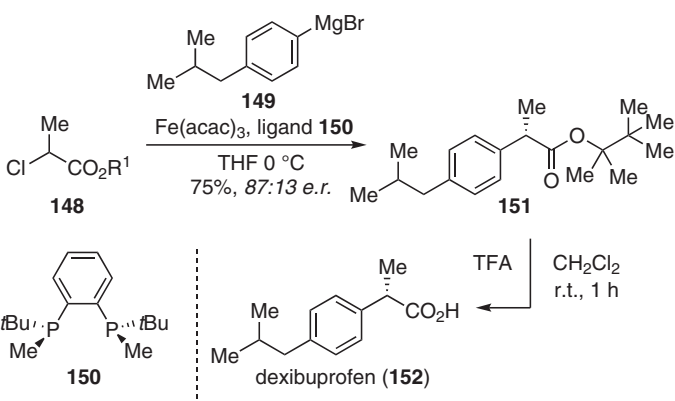

Scheme 17 (a) Fe-catalyzed sp $\mathrm{sp}^{3}-\mathrm{sp}^{2}$ cross-couplings to aryl Grignard reagents, ${ }^{58}$ (b) Suzuki and Negishi modifications, ${ }^{60,61 b}$ (c) cross-coupling to $\mathrm{CF}_{2} \mathrm{H}$ groups, ${ }^{62,63}$ (d) in situ reductive cross-coupling, ${ }^{64}$ (e) enantioselective cross-couplings and application to the synthesis of dexibuprofen ${ }^{43 e}$

\subsection{Fe-Catalyzed sp ${ }^{3}-\mathrm{sp}^{3}$ Cross-Coupling Reactions}

Fe-catalyzed $\mathrm{sp}^{3}-\mathrm{sp}^{3}$ cross-couplings are not as widespread as $\mathrm{sp}^{2}-\mathrm{sp}^{3}$ cross-coupling reactions. On the other hand, they possess high potential for the installation of $\mathrm{C}-\mathrm{C}$ bonds at $\mathrm{sp}^{3}$-hybridized positions of complex molecules.

Nakamura and co-workers used in situ hydroboration of terminal olefins followed by formation of the isopropylmagnesium bromide ate complex 154 to couple these activated boron nucleophiles to aliphatic halides. ${ }^{43 d}$ It should be mentioned that this transformation is also compatible with functional groups such as nitriles or esters (Scheme 18 , a). Fürstner and co-workers applied Fe(acac) $)_{3}$ cross-couplings to tosylated alkynyl cyclopropanes $156 .{ }^{65}$ Their pro- tocol provided all-carbon quaternary centers in good to excellent yields, whilst tolerating synthetically useful functional groups (Scheme 18, b).

(a) $s p^{3}-s p^{3}$ Suzuki cross-coupling (Nakamura 2012)

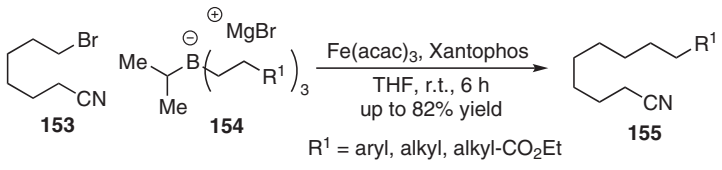

(b) Cross-coupings on cyclopropanes for the installation of all-carbon quaternary centers (Fürstner 2016)

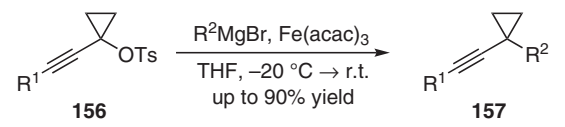

$\mathrm{R}^{1}=\mathrm{Ph}, \mathrm{CH}_{2} \mathrm{OPG} ; \mathrm{R}^{2}=$ alkyl, aryl, $\mathrm{CH}_{2} \mathrm{SiMe}_{3},\left(\mathrm{CH}_{2}\right)_{2}$-acetal

Scheme 18 (a) Fe-catalyzed $\mathrm{sp}^{3}-\mathrm{sp}^{3}$ Suzuki cross-couplings by Nakamura, ${ }^{43 d}$ and (b) Fürstner's cross-couplings on cyclopropanes ${ }^{65}$

\subsection{Fe-Catalyzed Cross-Coupling Reactions at sp Centers}

Similar to $\mathrm{sp}^{3}-\mathrm{sp}^{3}$ cross-couplings, transformations at sp-hybridized carbons are a remaining challenge. In this context, Meng and co-workers developed conditions for the homo-Glaser reaction of alkyne 158 with $\mathrm{Fe}(\mathrm{acac})_{3}$ and $\mathrm{Cu}$ (acac) $)_{2}$ as the co-catalyst (Scheme 19, a). ${ }^{66}$ Furthermore, not only are sp-sp couplings possible, but also combinations with $\mathrm{sp}^{2}$-hybridized halides. The nucleophilic alkyne 160 was activated by decarboxylation or direct $\mathrm{C}-\mathrm{H}$ oxidation at $140{ }^{\circ} \mathrm{C}$ (Scheme $\left.19, \mathrm{~b}\right) .{ }^{67}$

(a) Glaser coupling (Chen 2010)

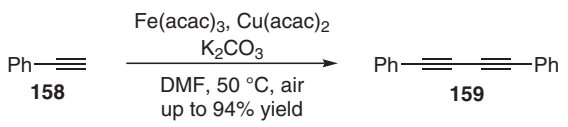

(b) Decarboxylative coupling to aryl halides (Mao 2011)

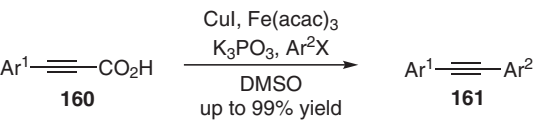

$$
\begin{aligned}
& \mathrm{X}=\mathrm{Br} \text {, I }
\end{aligned}
$$

Scheme 19 (a) Alkyne couplings in Glaser fashion, ${ }^{66}$ and (b) decarboxylative coupling of alkynes with aryl halides ${ }^{67}$

In the context of $\mathrm{Fe}(\mathrm{acac})_{3}$-catalyzed heteroarene syntheses there are only a limited number of methodology reports. However, there are numerous applications in total syntheses. Many of these have been summarized by Szostak and co-workers. ${ }^{56}$ A selected variety of $\mathrm{Fe}(\mathrm{acac})_{3}$-catalyzed cross-coupling reactions are illustrated in Scheme 20 (a). In most cases, chlorides are used to provide good selectivities for the cross-coupling reactions as the carbon-chlorine bond is the preferred site for Fe insertion. ${ }^{43 b, c, 51 e, 68}$ Furthermore, nitrogen-directed cross-coupling of heteroarenes can be performed regiospecifically under mild conditions. The 
substrate scope for generating tetrasubstituted pyrimidines 164 could be further extended by using tosylates or halides as coupling partners (Schemes 20, b and c). ${ }^{69,70}$ One example of how far this methodology can be extended was described by the group of Lee in their synthesis of SGLT2 inhibitor $170 .{ }^{71}$ They employed a $\mathrm{sp}^{2}-\mathrm{sp}^{3}$ cross-coupling reaction during the late stage of their synthesis and did so by differentiating between two distinct aryl chlorides (Scheme 20, d).

(a) General coupling scheme of heteroaromatics (Fürstner 2002 i.a.)

$$
\begin{aligned}
& \text { (Het)Ar-X } \stackrel{\mathrm{RMgBr}, \mathrm{Fe}(\mathrm{acac})_{3}}{\longrightarrow} \quad \text { (Het)Ar-R } \\
& 162 \quad 163 \\
& \mathrm{X}=\mathrm{Cl} \text {, OTf, OTs, OPO }(\mathrm{OEt})_{2}, \mathrm{OSO}_{2} \mathrm{NMe}_{2} \\
& \text { hetero } \mathrm{Ar}=\text { pyrimidine, pyridine, quinoline, quinozoline } \\
& \text { imidoyl-, thiophene, benzodifuran, benzothianzole, } \\
& \text { pyrazine, isoquinoline, 9-methyl-9H-purine }
\end{aligned}
$$

(b) Coupling of highly substitued pyrimidines (Wang 2015)

$$
\begin{gathered}
\text { RMgBr, } \mathrm{Fe}(\mathrm{acac})_{3} \\
\mathrm{TMEDA}
\end{gathered}
$$

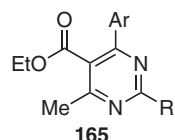

(c) Selective coupling of nucleoside-atttached pyrimidines (Hocek 2010)

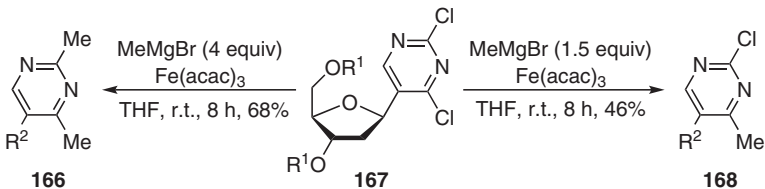

(d) Application to the synthesis of the SGLT2 inhibitor (Lee 2010)
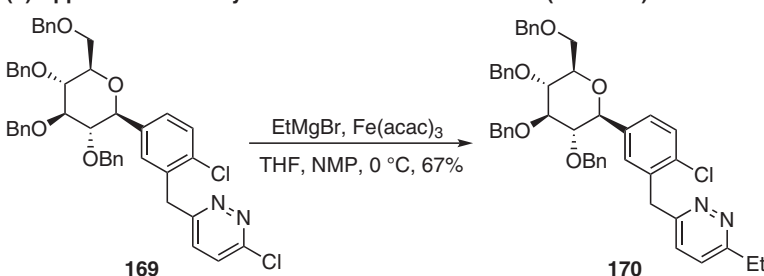

Scheme 20 (a) General approach to cross-couplings of heteroarenes, ${ }^{43 b, c, 51 e, 68}$ (b) selected examples of sterically challenging substrates, ${ }^{69}$ (c) couplings on nucleosides, ${ }^{70}$ and (d) application to the total synthesis of the SGLT2 inhibitor $\mathbf{1 7 0}$ by Lee and co-workers ${ }^{71}$

\subsection{Fe-Mediated Functionalization of C-H Bonds}

Common cross-coupling reactions require functional groups at specific positions to generate the new $\mathrm{C}-\mathrm{C}$ bond regiospecifically. In contrast, the direct functionalization of $\mathrm{C}-\mathrm{H}$ bonds partially simplifies this classical approach. To compensate for the omitted functional group, an external directing group is required to achieve good regio- and diastereoselectivity. ${ }^{1}$ Nakamura and co-workers reported such cross-coupling reactions under iron(III) catalysis on benzoquinoline system 171, directing the metal selectively to the $\gamma$-position of the aromatic nitrogen (Scheme 21, a). ${ }^{72}$ Further extensions of this work led to non-cyclic imines that were used for direct ortho-functionalization of arenes (Scheme 21, b). ${ }^{73}$ Interestingly, if an acetylated oxime is in proximity to the ortho-position $\mathrm{N}$-arylation takes place (Scheme 21, c). ${ }^{74}$ Besides aromatic substrates, the methodology was expanded to unsaturated amides. An additional ortho directing group (ODG) attached to the nitrogen is essential for coordinating the iron catalyst. This in turn is pivotal for the regioselective $\mathrm{C}-\mathrm{H}$ activation and for controlling the double bond geometry (Scheme 21, d).$^{75}$ Vishwakarma and co-workers reported $\mathrm{Fe}(\mathrm{acac})_{3}$-catalyzed Suzuki crosscoupling reactions of aryl boronic acids to pyrazine $\mathrm{C}-\mathrm{H}$ bonds instead of $\mathrm{C}$-halide bonds. This method was used for the installation of the aryl-pyrazine bond in the synthesis of botryllazine A (Scheme 21, e) ${ }^{76}$

\subsection{Fe-Catalyzed Ullmann Coupling Reactions}

Applications in the Ullmann coupling for the construction of biaryl ethers in excellent yields were published by

(a) $\mathrm{C}-\mathrm{H}$ coupling with a heteroaromatic directing effect (Nakamura 2008)

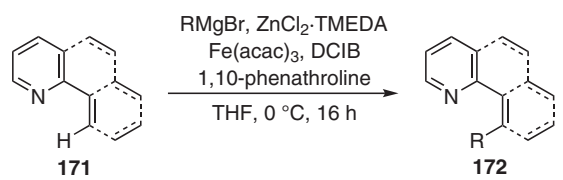

(b) $\mathrm{C}-\mathrm{H}$ coupling directed through imines (Nakamura 2009)

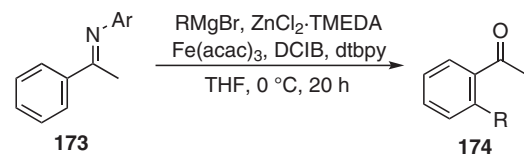

(c) Intramolecular N-Arylation of O-Acetyl Oximes (Yoshikai 2013)

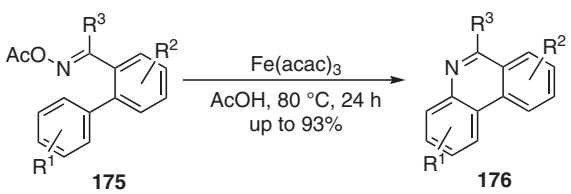

(d) C-H coupling with amide-tethered ODGs (Ackermann 2014)

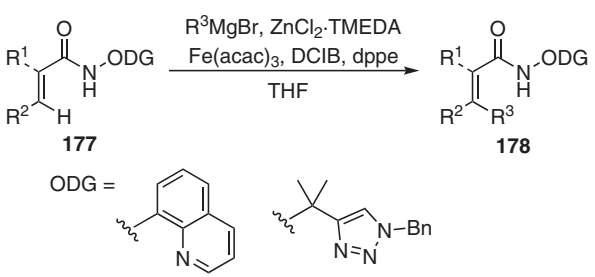

(e) Total synthesis of botryllazine A (Vishwakarma 2013)

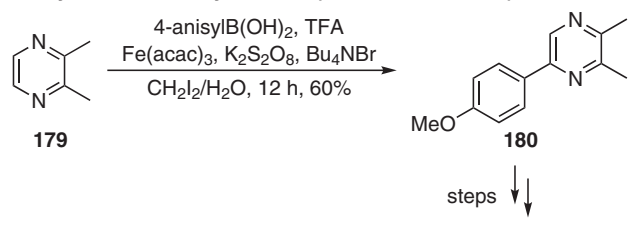

botryllazine $A$

Scheme 21 (a) Coupling of Grignard reagents to arene $\mathrm{C}-\mathrm{H}$ bonds, ${ }^{72}$ (b) and (c) $\mathrm{C}-\mathrm{H}$ coupling directed through imines, ${ }^{73,74}$ (d) $\mathrm{C}-\mathrm{H}$ coupling through amide-tethered ODGs, ${ }^{75}$ and (e) intermolecular $\mathrm{CH}$ coupling in Suzuki fashion; ${ }^{76} \mathrm{DCIB}=1,2$-dichloro-iso-butane, dtbpy $=4,4^{\prime}$-di-tertbutyl-2,2'-dipyridine, dppe $=1,2$-bis(diphenylphosphino)ethane) 
the Zhang group, who used a copper-iron co-catalyst system (Scheme 22, a). ${ }^{77 a-c}$ Further investigations led to double Ullmann reactions with 1,4-diiodo arenes, which can also be expanded to macrocyclizations of polyarylethers. ${ }^{77 \mathrm{~d}}$ Parallel to their work on biaryl ethers, Nakamura and co-workers investigated the coupling of primary aryl amines which were converted into the zincate and subsequently used for secondary amine formation (Scheme 22, b). ${ }^{78}$

(a) Fe(acac) $)_{3}$-catalyzed Ullmann cross-couplings (Zhang 2010)
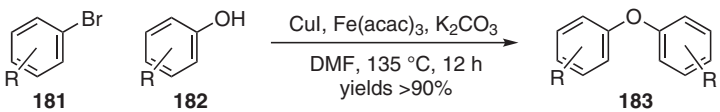

(b) UlImann couplings with primary amines (Nakamura 2011)

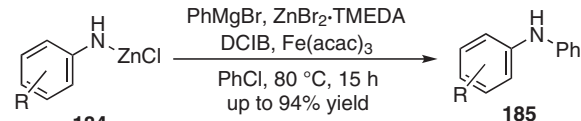

Scheme 22 (a) Fe(acac) $)_{3}$-catalyzed Ullmann-Goldberg cross-couplings, ${ }^{77 \mathrm{c}}$ and (b) Ullmann coupling of amines; ${ }^{78} \mathrm{DCIB}=1,2$-dichloroiso-butane

\subsection{Fe-Catalyzed Cross-Coupling of Acyl Chlorides}

Earlier, in 1984, Ronzini and co-workers described the $\mathrm{Fe}(\mathrm{acac})_{3}$-catalyzed cross-coupling of acyl chlorides to aliphatic or aromatic Grignard reagents (Scheme 23, a), ${ }^{79 a}$ and this research was later continued by the Fürstner group. ${ }^{79 b}$ The Dong group used Fe(acac) $)_{3}$ for the regio- and site-selective acylation and benzoylation of diols and carbohydrates (Scheme 23, b). ${ }^{80}$ The reagents of choice were the corresponding acyl chloride, Hünig's base and catalytic amounts of $\mathrm{Fe}(\mathrm{acac})_{3}$, which afforded the corresponding selectively protected alcohols 189 . While the common use of acyl chlorides is in coupling of the carbonyl moiety to other nucleo-

(a) Coupling of acid chlorides (Rizoni 1984 i.a.)

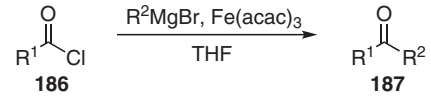

(b) Regio- and site-selective acylation of diols and carbohydrates containing a 1,2-cis-diol (Dong 2018)
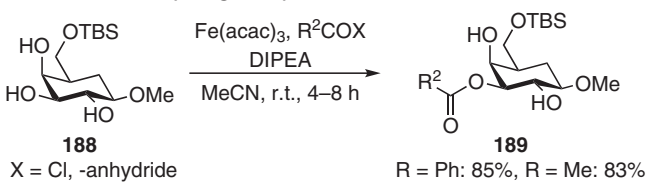

(c) Chlorination of silanes (Leino 2012)

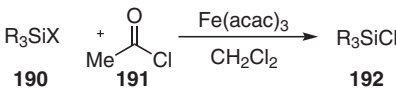

$$
\begin{aligned}
& \mathrm{X}=\mathrm{H}, \mathrm{OMe}, \mathrm{OH}
\end{aligned}
$$

Scheme 23 (a) Coupling of activated acyl chlorides to different Grignard reagents, ${ }^{79}$ (b) selective protection of carbohydrates, ${ }^{80}$ and (c) reversed reactivity of acyl chlorides for the synthesis of silyl chlorides ${ }^{81}$ philes, the Leino group published a method for the chlorination of silanes 190 (Scheme 23, c). ${ }^{81}$

\subsection{Fe-Catalyzed Allylations}

The Fe-catalyzed allylation of either aromatic or aliphatic Grignard reagents is possible by using allyl ethers or sulfonyl chlorides as electrophiles (Scheme 24, a). ${ }^{82}$ Furthermore, the direct functionalization of allylic $\mathrm{C}-\mathrm{H}$ bonds was reported by Nakamura and co-workers, which was also applicable to different substitution patterns on the allylic reagent (Scheme 24, b). ${ }^{83}$

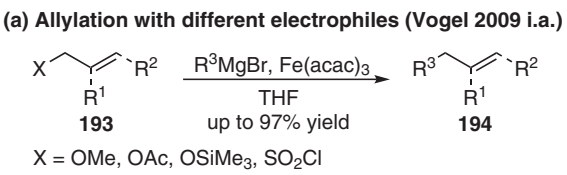

(b) Direct C-H oxidation allylation (Nakamura 2013)

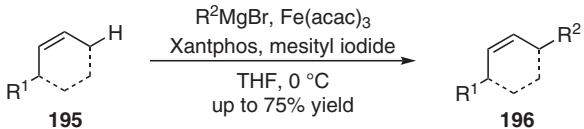

Scheme 24 (a) Electrophile allylations, ${ }^{82}$ and (b) direct C-H allylation ${ }^{83}$

\subsection{Miscellaneous Fe-Catalyzed Cross-Coupling Reactions}

Further applications using $\mathrm{Fe}(\mathrm{acac})_{3}$ were reported by Fürstner as a highly diastereoselective method for simultaneous ring-opening of 2-pyrones 197 (Scheme 25, a). ${ }^{84}$ This transformation is mechanistically proposed as 1,6-addition and reversion with the carboxylate as the leaving group. Furthermore, this strategy was used for the installation of the $Z / E$ diene moiety of granulatamide $B$ in $>10: 1$ d.r. (Scheme 25, b). ${ }^{84}$ Fürstner and Echeverria developed further reaction types of low-valent iron generated from $\mathrm{Fe}(\mathrm{III})$, where the iron reacts in a metalla-Alder-ene fashion with the ene-yne system to form metallacycle I (Scheme $25, \mathrm{c}){ }^{85}$ Instead of a direct reductive elimination, the addition of Grignard reagents opens the five-membered ring followed by reductive elimination of $\mathrm{Fe}(\mathrm{I})$ to build up the tetrasubstituted double bond of 202. The Nakamura group developed a protocol for insertion of iron into phenyl-iodo bonds followed by a 1,5 -HAT (Scheme 25 , d). ${ }^{86}$ The so-generated organoiron intermediate behaves similarly to established $\mathrm{sp}^{2}-\mathrm{sp}^{3}$ couplings. Overall, this transformation allows access to $\alpha$-functionalized pyrrolidines.

Devroy and co-workers used Fe-bpy, which was prepared from $\mathrm{Fe}(\mathrm{acac})_{3}$ in situ and investigated the [4+4] cycloisomerization of dienes with allyl ethers (Scheme 26). ${ }^{87}$ This transformation was also applied intramolecularly for amine- or ether-tethered substrates to give the corresponding trans-fused six-membered rings $\mathbf{2 0 6}^{87}$ 
(a) Formal ring opening of 2-pyrones (Fürstner 2013)

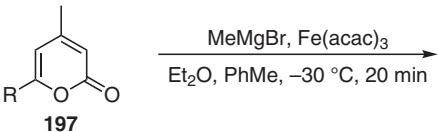<smiles>[2H]/C(C)=C/C(C)=C/C(=O)O</smiles>

(b) Application of 2-pyrone opening to the total synthesis of granulatamide B<smiles>CCOC(C)Cc1cc(C)cc(=O)o1</smiles>

granulatamide B

(c) Cycloisomerization-cross-coupling (Fürstner 2016)

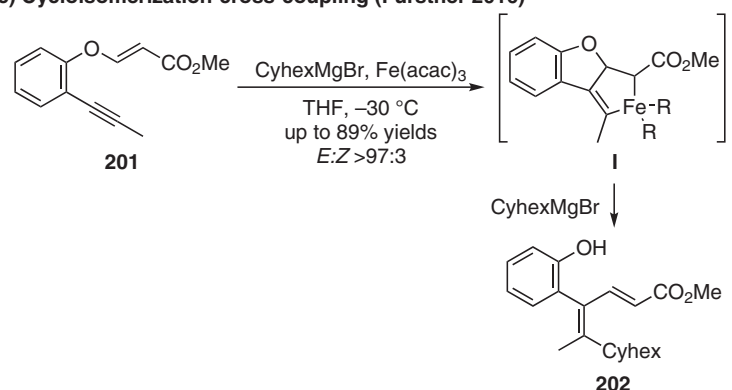

(d) Cross-coupling via 1,5-HAT (Nakamura 2010)
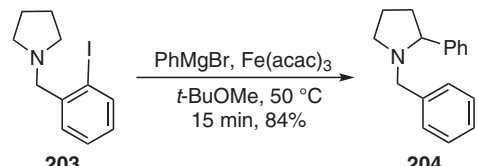

Scheme 25 (a) Opening of 2-pyrones to highly substituted dienes, ${ }^{84}$ (b) application of this method toward the total synthesis of granulatamide $B{ }^{84}$ (c) Fürstner's cycloisomerization-cross-coupling approach, ${ }^{85}$ and (d) a tandem 1,5-HAT-Kumada cross-coupling ${ }^{86}$

[4+4] Cycloisomerization with Fe-bpy (Devroy 1986 i.a.)

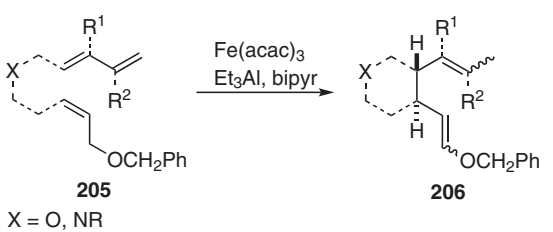

Scheme 26 Fe-byp-catalyzed [4+4] cycloisomerization of dienes with allylic ethers ${ }^{87}$

\section{Borylations}

Besides the tremendously broad field of $\mathrm{Fe}(\mathrm{acac})_{3}$-mediated cross-couplings, borylations of alkyl or aryl halides have been reported in the literature. In 2014, Cook and coworkers published the borylation of various alkyl halides 207 with bispinacolato diboron and provided a very broad scope of substrates $\mathbf{2 0 8}$ (Scheme 27, a). ${ }^{88}$ The electrophiles of choice were chlorides, bromides, iodides and tosylates, with bromides giving the best results in up to $95 \%$ yield. Borylations of aryl chlorides $\mathbf{2 0 9}$ were reported by Nakamura in 2017 using bispinacolato diboron in the presence of po- tassium tert-butoxide at elevated temperature, albeit with a limited substrate scope (Scheme 27, b).${ }^{89}$ Coupling of pinacolato borane 212 with aryl bromides 211 using iron-copper catalysis has been described by Chavant in yields of up to $81 \%$ (Scheme 27, c). ${ }^{90}$

(a) Borylation of alkyl electrophiles (Cook 2014)

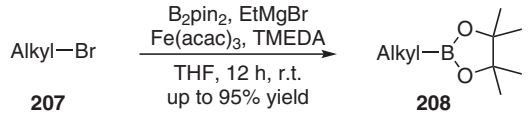

(b) Borylation of aryl chlorides (Nakamura 2017)

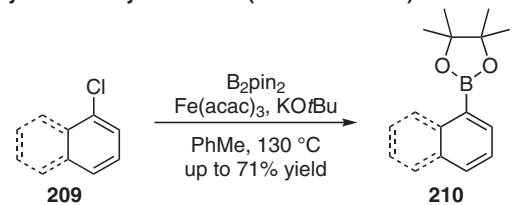

(c) Borylation of aryl bromides using pinacolato borane (Chavant 2014)

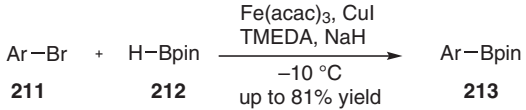

Scheme 27 (a) Cook's borylation of sp $^{3}$ electrophiles, ${ }^{88}$ (b) Nakamura's borylation of aryl chlorides, ${ }^{89}$ and (c) Chavant's borylation of aryl bromides $^{90}$

In 2017 Findlater and Tamang showed that it was possible to obtain the corresponding alcohol 216 through the Fecatalyzed hydroboration of aldehydes or ketones 214. It is proposed that this reaction proceeds via alkoxyboron species 215, which delivers alcohol 216 under standard workup conditions (Scheme 28). ${ }^{91}$

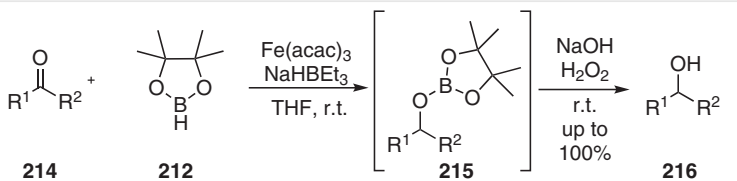

$\mathrm{R}^{1}=$ aryl, alkyl; $\mathrm{R}^{2}=\mathrm{H}$, alkyl, aryl

Scheme 28 Hydroboration of aldehydes and ketones by Findlater and Tamang ${ }^{91}$

\section{Miscellaneous Reactions}

Additional transformations highlight the great potential of $\mathrm{Fe}(\mathrm{acac})_{3}$ catalysis and synthesis. The Kirihara group published a selective and efficient method for dedithioacetalizations of 2-silylated 1,3-dithianes 217. In these transformations the use of $\mathrm{Fe}(\mathrm{acac})_{3}$ in combination with NaI and hydrogen peroxide greatly improves the yields of the corresponding acyl silanes $\mathbf{2 1 8}$ compared to other well-established protocols (Scheme 29, a). ${ }^{92}$ The same conditions were applied for oxidative cleavage of aryl-, vinyl-, and alkyl-substituted dithianes $\mathbf{2 1 9}$ in up to quantitative yields (Scheme 29, b). ${ }^{93}$ 
(a) Catalytic dedithioacetalization of 2-silyl-1,3-dithianes (Kirihara 2017)

$$
\begin{aligned}
& \overbrace{\mathrm{S}}^{\mathrm{S}}<_{\mathrm{Si}^{*}}^{\mathrm{S}} \frac{\mathrm{Fe}(\mathrm{acac})_{3}, \mathrm{Nal}}{30 \% \mathrm{H}_{2} \mathrm{O}_{2}} \underset{\mathrm{R}^{\mathrm{EtOAc} / \mathrm{H}_{2} \mathrm{O}(1: 1)}}{\text { r.t. }} \mathrm{N}_{\mathrm{Si}^{*}} \\
& 217 \text { up to quant. yields } 218
\end{aligned}
$$

$\mathrm{R}=$ aryl, alkyl; $\mathrm{Si}^{*}=\mathrm{TMS}, \mathrm{TES}, \mathrm{TBS}, \mathrm{TIPS}$, TBDPS

(b) Catalytic dedithioacetalization of dithianes (Kirihara 2013)

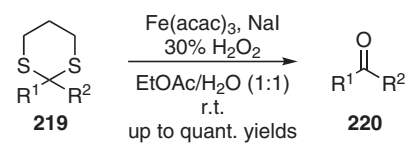$$
\mathrm{R}^{1}=\text { aryl, vinyl, alkyl; } \mathrm{R}^{2}=\text { aryl, alkyl, } \mathrm{H}
$$

Scheme 29 (a) Catalytic dedithioacetalization of dithianes to obtain acyl silanes, ${ }^{92}$ and (b) aldehydes or ketones ${ }^{93}$

A tremendously broad scope of substrates for transesterifications of different alcohols with different esters was described by Weng and co-workers in 2011 (Scheme 30, a) ${ }^{94}$ An approach toward the diversity-oriented ketodiol 226 via didecarboxylative bidirectional aldolization of diacid 224 was published by Rodriguez (Scheme 30, b). ${ }^{95}$ A different type of reaction is the intermolecular heterocoupling of enolates described by the Baran group to synthesize the corresponding 1,4-diketones $\mathbf{2 2 9}$ (Scheme 30, c). The mechanism is proposed to proceed via an oxidative radical phenol coupling type mechanism. ${ }^{96}$ Further, Hayashi and Saski published a pinacol coupling of aryl ketone $\mathbf{2 3 0}$ with a phenyltitanium reagent in the presence of $\mathrm{Fe}(\mathrm{acac})_{3}$ to afford the corresponding pinacol 231 (Scheme 30, d). ${ }^{97}$ The initial step is a reductive cross-coupling of the phenyl substituent to generate a low-valent titanium species. This titanium species subsequently catalyzes the pinacol coupling.

An additional variation to carbometalations of alkynes and allenes is the hydromagnesiation of olefins. Subsequent addition of carbon dioxide generates the corresponding carboxylic acids. This was applied by Thomas and co-workers to the synthesis of ibuprofen rac-(152) (Scheme 31, a). ${ }^{98}$ $( \pm)$-Baclophen ${ }^{99 \mathrm{a}}$ and $( \pm)$-rolipram ${ }^{99 \mathrm{~b}}$ were synthesized due to their pharmacological relevance via an $\mathrm{Fe}(\mathrm{acac})_{3}$-mediated Michael addition of nitromethane to $\alpha$-cyano cinnamic ester 234 (Scheme 31, b). ${ }^{99}$

A rather mild approach for the reduction of nitroarene 235 with different substitution patterns to the corresponding anilines 236 was published by Lemaire and co-workers in 2010 (Scheme 32). ${ }^{100}$ This iron-mediated reduction in the presence of TMDS tolerates various functional groups, such as esters, aldehydes, carboxylic acids, bromides, etc., and affords the corresponding anilines $\mathbf{2 3 6}$ as the hydrochloride salts in excellent yields (Scheme 32, a). In 2018, Gennari and co-workers ${ }^{101}$ published an asymmetric reduction of imine 237 using a modified chiral Knölker-type catalyst ${ }^{102}$ and obtained, in the presence of $\mathrm{Fe}(\mathrm{acac})_{3}$, high conversions with moderate selectivities (Scheme 32, b). Another (a) Transesterification (Weng 2011)

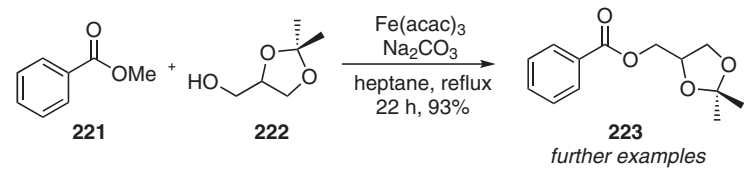

(b) Didecarboxylative bidirectional aldolization (Rodriguez 2015)

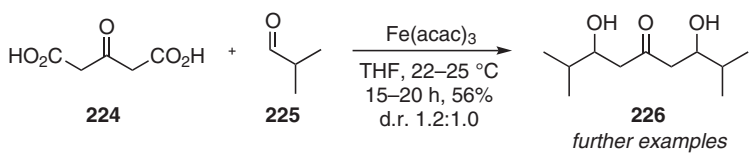

(c) Intermolecular enolate heterocoupling (Baran 2008)

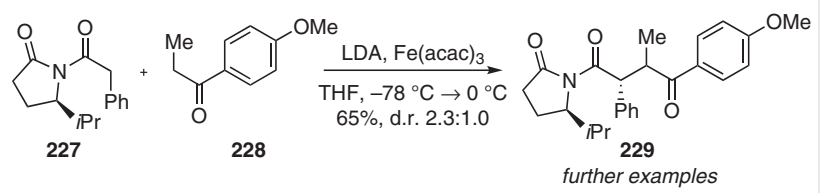

(d) Pinacol coupling of aryl ketones (Hayashi 2011)

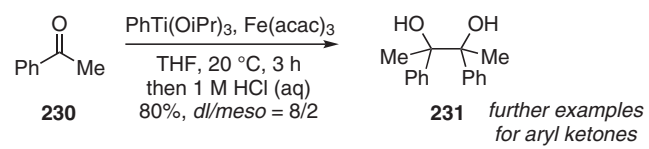

Scheme 30 (a) Selected example of Weng's transesterification, ${ }^{94}$ (b) didecarboxylative bidirectional aldolization by Rodriguez, ${ }^{95}$ (c) Baran's intermolecular enolate heterocoupling, ${ }^{96}$ and (d) Hayashi's pinacol coupling of aryl ketones ${ }^{97}$

(a) Hydromagnesiation strategy for the synthesis of ibuprofen (Thomas 2014)

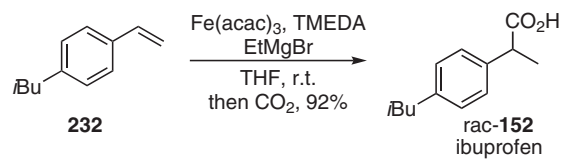

(b) Michael addition/Pinner reaction toward the synthesis of baclophen (Chopade 2015)

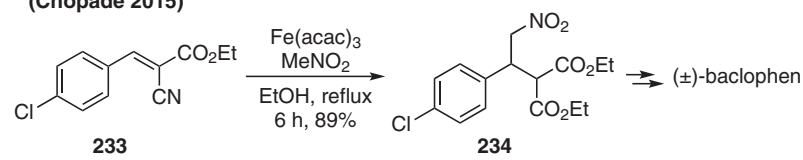

Scheme 31 Synthesis of small, medicinally relevant molecules: (a) Hydromagnesiation toward the synthesis of ibuprofen by Thomas, ${ }^{98}$ and (b) synthesis toward baclophen by Chopade ${ }^{99}$

$\mathrm{Fe}(\mathrm{acac})_{3}$-mediated reaction is Bolm's imination of sulfoxide 239 which proceeds with complete retention of configuration at the sulfur center and affords sulfoximine 241. ${ }^{103}$ The same transformation is applicable to sulfides and provides sulfimines in very good yields (Scheme $32, \mathrm{c}){ }^{103}$

The synthesis of several heterocyclic structures has been shown in the field of $\mathrm{Fe}(\mathrm{acac})_{3}$-mediated synthetic chemistry. ${ }^{56}$ In 2010, Yoon and Williamson published a synthetic access to 1,3-oxazolidines 243 by aminohydroxylation of olefins 242 using $\mathrm{N}$-sulfonyl oxaziridines (Scheme 33, a). ${ }^{104}$ This aminohydroxylation strategy was applied to the synthesis of $( \pm)$-octopamine. ${ }^{104}$ Bao employed radical conditions for the synthesis of 3-amido-oxindole 246 from 
(a) Selective reduction of nitroarenes to anilines (Lemaire 2010)

$$
235 \underbrace{\mathrm{Fe}(\mathrm{acac})_{3}, \mathrm{TMDS}}_{\begin{array}{c}
\mathrm{THF}, 60^{\circ} \mathrm{C}, 24 \mathrm{~h} \\
\text { then } \mathrm{HCl}(\mathrm{aq}), 92 \%
\end{array}}
$$

(b) Asymmetric reduction of imines (Gennari 2018)

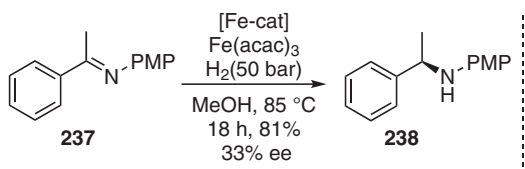

(c) Imination of sulfoxides and sulfides (Bolm 2006)

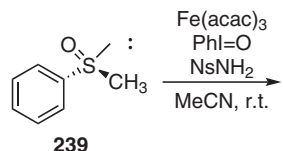

$83 \%$ ee

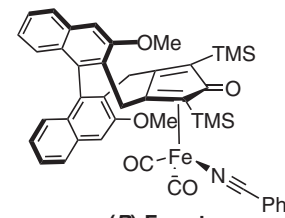

(R)-Fe-cat

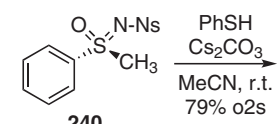

further examples

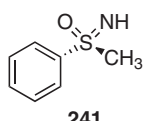

$83 \%$ ee
Scheme 32 (a) Selective reduction of nitroarenes to anilines by Lemaire, ${ }^{100}$ (b) asymmetric reduction using chiral (cyclopentadienone)iron complexes by Gennari, ${ }^{101}$ and (c) imination of sulfoxides and sulfides by Bolm; ${ }^{103}$ TMDS = 1,1,3,3-tetramethyldisilazane, Ns = nosyl, $\mathrm{o} 2 \mathrm{~s}=$ yield over two steps.

aromatic $i$-propenylamides 244 and $\gamma$-butyrolactam 242 (Scheme 33, b). ${ }^{105}$ Furthermore, Prins cyclizations of homopropargylic alcohols and amines $\mathbf{2 4 7}$ were reported by Padrón and co-workers (Scheme 33, c). ${ }^{106}$ By using aldehydes in combination with TMSI the iodinated unsaturated heterocycle $\mathbf{2 4 8}$ was obtained. A very different example is the synthesis of benzo[b]thiophenes $\mathbf{2 5 0}$ by Che in 2011. ${ }^{107}$ They demonstrated that $\mathrm{Fe}(\mathrm{acac})_{3}$ is not only the catalyst but also the source of acetylacetone as the reagent. Therefore, one ligand on the iron is exchanged by thiosalicylic acid 249 and thus liberates acetylacetone for the subsequent transformation (Scheme 33). ${ }^{107}$

\section{Conclusions}

Even though $\mathrm{Fe}(\mathrm{acac})_{3}$ is broadly applicable in organic synthesis, a large variety of improvements are observed in the area of cross-coupling reactions. The remarkable functional group tolerance as well as its applicability to alkyl reagents illustrates the significance of $\mathrm{Fe}(\mathrm{acac})$-catalyzed cross-coupling reactions. Additionally, the field of HAT-initiated transformations enables new pathways to complex natural products. Considering the relatively young area of this research, one can anticipate even more relevant contributions in the future. (a) Aminohydroxylation of olefins via 1,3-oxazolidines (Yoon 2010)

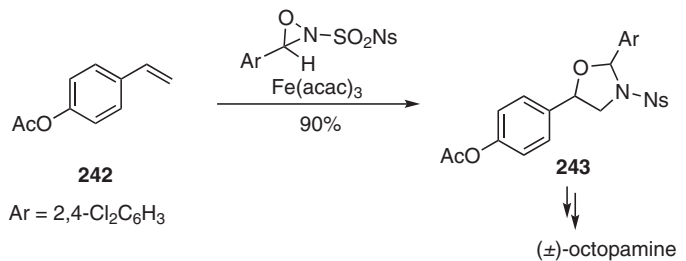

(b) Convenient synthesis toward 3-amido-oxindoles (Bao 2015)

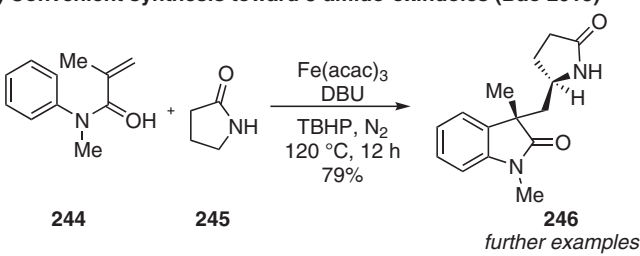

(c) Catalytic Prins cyclization (Padron 2009)

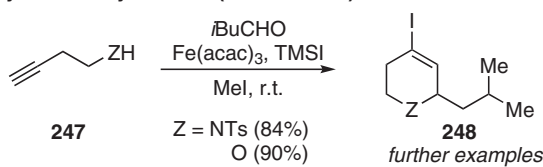

(d) Synthesis of benzo[b]thiophenes via a one-pot reaction (Che 2011)

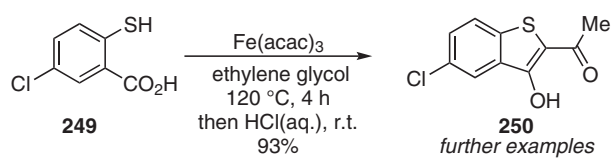

Scheme 33 (a) 1,3-Oxazolidine formation by Yoon, ${ }^{104}$ (b) synthesis of 3-amido-oxindoles by Bao, ${ }^{105}$ (c) catalytic Prins cyclization by Padrón, ${ }^{106}$ and $(d)$ synthesis of benzo[b]thiophenes by $\mathrm{Che}^{107}$

\section{References}

(1) (a) Bauer, I.; Knölker, H.-J. Chem. Rev. 2015, 115, 3170. (b) For cross-couplings in natural product syntheses, see also: Legros, J.; Figadère, B. Nat. Prod. Rep. 2015, 32, 1541.

(2) Fürstner, A. ACS Cent. Sci. 2016, 2, 778.

(3) (a) Yoshida, I.; Kobayashi, H.; Ueno, K. Bull. Chem. Soc. Jpn. 1974, 47, 2203. (b) Chaudhuri, M. K.; Ghosh, S. K. J. Chem. Soc., Dalton Trans. 1983, 839.

(4) Isayama, S.; Mukaiyama, T. Chem. Lett. 1989, 18, 1071.

(5) (a) Simonneau, A.; Oestreich, M. Angew. Chem. Int. Ed. 2015, 54, 3556; Angew. Chem. 2015, 127, 3626. For further reviews on HAT-based olefin functionalization, see: (b) Crossley, S. W. M.; Obradors, C.; Martinez, R. M.; Shenvi, R. A. Chem. Rev. 2016, 116, 8912. (c) Gao, S.; Qui, Y. Sci. China Chem. 2016, 59, 1093.

(6) (a) Lo, J. C.; Yabe, Y.; Baran, P. S. J. Am. Chem. Soc. 2014, 136, 1304. (b) Lo, J. C.; Gui, J.; Yabe, Y.; Pan, C.-M.; Baran, P. S. Nature 2014, 516, 343. (c) Lo, J. C.; Kim, D.; Pan, C.-M.; Edwards, J. T.; Yabe, Y.; Gui, J.; Qin, T.; Gutierrez, S.; Giacoboni, J.; Smith, M. W.; Holland, P. L.; Baran, P. S. J. Am. Chem. Soc. 2017, 139, 2484.

(7) Obradors, C.; Martinez, R. M.; Shenvi, R. A. J. Am. Chem. Soc. 2016, $138,4962$.

(8) Dao, H. T.; Li, C.; Michaudel, Q.; Maxwell, B. D.; Baran, P. S. J. Am. Chem. Soc. 2015, 137, 8046. 
(9) Gui, J.; Pan, C.-M.; Jin, Y.; Quin, T.; Lo, J. C.; Lee, B. J.; Spergel, S. H.; Mertzman, M. E.; Pitts, W. J.; La Cruz, T. E.; Schmidt, M. A.; Darvatkar, N.; Natarajan, S. R.; Baran, P. S. Science 2015, 348, 886.

(10) Deng, Z.; Chen, C.; Cui, S. RCS Adv. 2016, 6, 93753.

(11) (a) Beckwith, A. L. J.; Hay, B. P. J. Am. Chem. Soc. 1989, 111, 230. (b) Beckwith, A. L. J.; Hay, B. P. J. Am. Chem. Soc. 1989, 111, 2674.

(12) Saladrigas, M.; Bosch, C.; Saborit, G. V.; Bonjoch, J.; Bradshaw, B. Angew. Chem. Int. Ed. 2018, 57, 182; Angew. Chem. 2018, 130, 188.

(13) George, D. T.; Kuenstner, E. J.; Pronin, S. V. J. Am. Chem. Soc. 2015, 137, 15410.

(14) Deng, H.; Cao, W.; Liu, R.; Zhang, Y.; Liu, B. Angew. Chem. Int. Ed. 2017, 56, 5849; Angew. Chem. 2017, 129, 5943.

(15) Ruider, S. A.; Sandmeier, T.; Carreira, E. M. Angew. Chem. Int. Ed. 2015, 54, 2378; Angew. Chem. 2015, 127, 2408.

(16) Tohama, M.; Tomita, T.; Kimura, M. Tetrahedron Lett. 1973, 44, 4359.

(17) Kimura, M.; Muto, T. Chem. Pharm. Bull. 1979, 27, 109.

(18) Muto, T.; Tanaka, J.; Miura, T.; Kimura, M. Chem. Pharm. Bull. 1983, 31, 1561.

(19) Muto, T.; Tanaka, J.; Miura, T.; Kimura, M. Chem. Pharm. Bull. 1982, 30, 3172

(20) Dell'Anna, M. M.; Mastrorilli, P.; Nobile, C. F.; Lopez, L. J. Mol. Catal. A: Chem. 1996, 111, 33.

(21) Song, H.; Kang, B.; Hong, S. H. ACS Catal. 2014, 4, 2889.

(22) Iwata, S.; Hata, T.; Urabe, H. Adv. Synth. Catal. 2012, 354, 3480.

(23) Morisson, V.; Barnier, J.-P.; Blanco, L. Tetrahedron Lett. 1999, 40, 4045.

(24) Zhao, J.; Zhou, W.; Han, J.; Li, G.; Pan, Y. Tetrahedron Lett. 2013, $54,6507$.

(25) Zhao, J.; Fang, H.; Han, J.; Pan, Y. Beilstein J. Org. Chem. 2013, 9, 1718.

(26) Mir, B. A.; Banerjee, A.; Santra, S. K.; Rajamanickam, S.; Patel, B. K. Adv. Synth. Catal. 2016, 358, 3471.

(27) Lehr, K.; Schulthoff, S.; Ueda, Y.; Mariz, R.; Leseurre, L.; Gabor, B.; Fürstner, A. Chem. Eur. J. 2015, 21, 219.

(28) Kessler, S. N.; Bäckvall, J.-E. Angew. Chem. Int. Ed. 2016, 55, 3734; Angew. Chem. 2016, 128, 3798.

(29) Fürstner, A.; Mendez, M. Angew. Chem. Int. Ed. 2003, 42, 5355; Angew. Chem. 2003, 115, 5513.

(30) Sherry, B. D.; Fürstner, A. Chem. Commun. 2009, 7116.

(31) (a) Fürstner, A.; Kattnig, E.; Lepage, O. J. Am. Chem. Soc. 2006, 128, 9194. (b) Lepage, O.; Kattnig, E.; Fürstner, A. J. Am. Chem. Soc. 2004, 126, 15970.

(32) Matsumoto, A.; Ilies, L.; Nakamura, E. J. Am. Chem. Soc. 2011, $133,6557$.

(33) Ilies, L.; Arslanoglu, Y.; Matsubara, T.; Nakamura, E. Asian J. Org. Chem. 2018, 7, 1327.

(34) See: Knochel, P. In Comprehensive Organic Synthesis; Trost, B. M.; Fleming, I.; Semmelhack, M. F., Ed.; Pergamon Press: New York, 1991, 865-911.

(35) Hojo, M.; Murakami, Y.; Aihara, H.; Sakuragi, R.; Baba, Y.; Hosomi, A. Angew. Chem. Int. Ed. 2001, 40, 621; Angew. Chem. 2001, 113, 641 .

(36) Shirakawa, E.; Yamagami, T.; Kimura, T.; Yamaguchi, S.; Hayashi, T. J. Am. Chem. Soc. 2005, 127, 17164.

(37) Yamagami, T.; Shintani, R.; Shirakawa, E.; Hayashi, T. Org. Lett. 2007, 9, 1045

(38) Lu, Z.; Chai, G.; Ma, S. J. Am. Chem. Soc. 2007, 129, 14546.

(39) Zhang, D.; Ready, J. M. J. Am. Chem. Soc. 2006, 128, 15050.

(40) Guo, S.; Liu, J.; Ma, D. Angew. Chem. Int. Ed. 2015, 54, 1298; Angew. Chem. 2015, 127, 1314.
(41) Tamao, K.; Sumitani, K.; Kumada, M. J. Am. Chem. Soc. 1972, 94, 4374.

(42) Kharash, M. S.; Fields, E. K. J. Am. Chem. Soc. 1941, 63, 2316.

(43) (a) Smith, R. S.; Kochi, J. K. J. Org. Chem. 1976, 41, 502. (b) Fürstner, A.; Leitner, A. Angew. Chem. Int. Ed. 2002, 41, 609; Angew. Chem. 2002, 114, 632. (c) Fürstner, A.; Leitner, A.; Mendez, M.; Krause, H. J. Am. Chem. Soc. 2002, 124, 13856. (d) Hatakeyama, T.; Hashimoto, T.; Kathriarachchi, K. K. A. D. S.; Zenmyo, T.; Seike, H.; Nakamura, M. Angew. Chem. Int. Ed. 2012, 51, 8834; Angew. Chem. 2012, 124, 8964. (e) Jin, M.; Adak, L.; Nakamura, M. J. Am. Chem. Soc. 2015, 137, 7128.

(44) (a) Cassani, C.; Bergonzini, G.; Wallentin, C.-J. ACS Catal. 2016, 6 , 1640. (b) Bedford, R. B. Acc. Chem. Res. 2015, 48, 1485.

(45) Parchomyk, T.; Koszinowski, K. Chem. Eur. J. 2016, 22, 15609.

(46) (a) Fabré, J.-L.; Julia, M.; Verpeaux, J.-N. Tetrahedron Lett. 1982, 23, 2469. (b) Dohle, W.; Kopp, F.; Cahiez, G.; Knochel, P. Synlett 2001, 1901. (c) Dunet, G.; Knochel, P. Synlett 2006, 407. (d) Itami, K.; Higashi, S.; Mineno, M.; Yoshida, J.-I. Org. Lett. 2004, 7, 1219.

(47) Xu, X.; Cheng, D.; Pei, W. J. Org. Chem. 2006, 71, 6637.

(48) Chen, Y.; Huang, Y.; Zhao, X.; Li, Z. Synth. Commun. 2015, 45, 734.

(49) Adams, K.; Ball, A. K.; Birkett, J.; Brown, L.; Chappell, B.; Gill, D. M.; Lo, P. K. T.; Patmore, N. J.; Rice, C. R.; Ryan, J.; Raubo, P.; Sweeney, J. B. Nat. Chem. 2017, 9, 396.

(50) Munoz, S. B. III.; Daifuku, S. L.; Sears, J. D.; Baker, T. M.; Carpenter, S. H.; Brennessel, W. W.; Neidig, M. L. Angew. Chem. Int. Ed. 2018, 57, 6496; Angew. Chem. 2018, 130, 6606.

(51) (a) Tee, O. S.; Du, X.-X. J. Org. Chem. 1988, 53, 1839. (b) Hashmi, A. S. K.; Szeimies, G. Chem. Ber. 1994, 127, 1075. (c) Seck, M.; Franck, X.; Hocquemiller, R.; Figadère, B.; Peyrat, J.-F.; Provot, O.; Brion, J.-D.; Alami, M. Tetrahedron Lett. 2004, 45, 1881. (d) Schneider, B.; Bonnekessel, M.; Krause, H.; Fürstner, A. J. Org. Chem. 2004, 69, 3943. (e) Silveira, C. C.; Mendes, S. R.; Wolf, L. J. Braz. Chem. Soc. 2010, 21, 2138. (f) Gülak, S.; Gieshoff, T. N.; von Wangelin, A. J. Adv. Synth. Catal. 2013, 355, 2197. (g) Guo, W.-J.; Wang, Z.-X. Tetrahedron 2013, 69, 9580. (h) Shakhmaev, R. N.; Sunagatullina, A. S.; Zorin, V. V. Russ. J. Org. Chem. 2014, 50, 322. (i) Piontek, A.; Szostak, M. Eur. J. Org. Chem. 2017, 7271.

(52) Nishikado, H.; Nakatsuji, H.; Ueno, K.; Nagase, R.; Tanabe, Y. Synlett 2010, 2087.

(53) (a) Cahiez, G.; Gager, O.; Habiak, V. Synthesis 2008, 2636. (b) Cahiez, G.; Habiak, V.; Gager, O. Org. Lett. 2008, 10, 2389.

(54) (a) Cahiez, G.; Marquais, S. Tetrahedron Lett. 1996, 37, 1773. (b) Cahiez, G.; Chaboche, C.; Duplais, C.; Moyeux, A. Org. Lett. 2009, 11, 277.

(55) Czaplik, W.; Gruppe, S.; Mayer, M.; von Wangelin, A. J. Chem. Commun. 2010, 46, 6350.

(56) Piontek, A.; Bisz, E.; Szostak, M. Angew. Chem. Int. Ed. 2018, 57, 11116; Angew. Chem. 2018, 130, 11284.

(57) Barbier, J.; Jansen, R.; Irschik, H.; Benson, S.; Gerth, K.; Böhlendorf, B.; Höfle, G.; Reichenbach, H.; Wegner, J.; Zeilinger, C.; Kirschning, A.; Müller, R. Angew. Chem. Int. Ed. 2012, 51, 1256; Angew. Chem. 2012, 124, 1282.

(58) (a) Nagano, T.; Hayashi, T. Org. Lett. 2004, 6, 1297. (b) Cahiez, G.; Habiak, V.; Duplais, C.; Moyeux, A. Angew. Chem. Int. Ed. 2007, 46, 4363; Angew. Chem. 2007, 123, 4442. (c) Volla, C. M. R.; Vogel, P. Angew. Chem. Int. Ed. 2008, 47, 1305; Angew. Chem. 2008, 120, 1325. (d) Denmark, S. E.; Cresswell, A. J. J. Org. Chem. 2013, 78, 12593. (e) Parmar, D.; Henkel, L.; Dib, J.; Rueping, M. Chem. Commun. 2015, 51, 2111.

(59) Miyaura, N.; Yamada, K.; Suzuki, A. Tetrahedron Lett. 1979, 36, 3437. 
(60) Bedford, R. B.; Brenner, P. B.; Certer, E.; Carvell, T. W.; Cogswell, P. M.; Gallagher, T.; Harvey, J. N.; Murphy, D. M.; Neeve, E. C.; Nunn, J.; Pye, D. R. Chem. Eur. J. 2014, 20, 7935.

(61) (a) King, A. O.; Okukado, N.; Negishi, E. Chem. Commun. 1977, 683. (b) Hatakeyama, T.; Nakagawa, N.; Nakamura, M. Org. Lett. 2009, 11, 4496.

(62) Feng, Z.; Min, Q.-Q.; Zhang, X. Org. Lett. 2016, 18, 44.

(63) Miao, W.; Zhao, Y.; Ni, C.; Gao, B.; Zhang, W.; Hu, J. J. Am. Chem. Soc. 2018, 140, 880.

(64) Savela, R.; Majewski, M.; Leino, R. Eur. J. Org. Chem. 2014, 4137.

(65) Tindall, D. J.; Krause, H.; Fürstner, A. Adv. Synth. Catal. 2016, 358, 2398.

(66) Meng, X.; Li, C.; Han, B.; Wang, T.; Chen, B. Tetrahedron 2010, 66, 4029.

(67) (a) Volla, C. M. R.; Vogel, P. Tetrahedron Lett. 2008, 49, 5961. (b) Li, T.; Qu, X.; Zhu, Y.; Sun, P.; Yang, H.; Shan, Y.; Zhang, H.; Liu, D.; Zhang, X.; Mao, J. Adv. Synth. Catal. 2011, 353, 2731.

(68) (a) Ottesen, L. K.; Ek, F.; Olsson, R. Org. Lett. 2006, 8, 1771. (b) Gøgsig, T.; Lindhardt, A. T.; Skrydstrup, T. Org. Lett. 2009, 11, 4886.

(69) Chen, X.; Quan, Z.-J.; Wand, X.-C. Appl. Organomet. Chem. 2015, 29, 296.

(70) Kubelka, T.; Slavetinská, L.; Klepetárová, B.; Hocek, M. Eur.J. Org. Chem. 2010, 2666.

(71) Kim, M. J.; Lee, J.; Kang, S. Y.; Lee, S.-H.; Son, E.-J.; Jung, M. E.; Lee, S. H.; Song, K.-S.; Lee, M. W.; Han, H.-K.; Kim, J.; Lee, J. Bioorg. Med. Chem. Lett. 2010, 20, 3420.

(72) (a) Norinder, J.; Matsumoto, A.; Yoshikai, N.; Nakamura, E. J. Am. Chem. Soc. 2008, 130, 5858. (b) Ilies, L.; Tsuji, H.; Nakamura, E. Org. Lett. 2009, 11, 3966. (c) Ilies, L.; Okabe, J.; Yoshikai, N.; Nakamura, E. Org. Lett. 2010, 12, 2838. (d) Yoshikai, N.; Matsumoto, A.; Norinder, J.; Nakamura, E. Synlett 2010, 313. (e) Ilies, L.; Asako, S.; Nakamura, E. J. Am. Chem. Soc. 2011, 133, 7672. (f) Yoshikai, N.; Asako, S.; Yamakawa, T.; Ilies, L.; Nakamura, E. Chem. Asian J. 2011, 6, 3059.

(73) (a) Yohsokai, N.; Matsumoto, A.; Norinder, J.; Nakamura, E. Angew. Chem. Int. Ed. 2009, 48, 2925; Angew. Chem. 2009, 121, 2969. (b) Sirois, J. J.; Davis, R.; DeBoef, B. Org. Lett. 2014, 16, 868.

(74) (a) Deb, I.; Yoshikai, N. Org. Lett. 2013, 15, 4254. (b) Zhang, Z.; Li, J.; Zhang, G.; Ma, N.; Liu, Q.; Liu, T.J. Org. Chem. 2015, 80, 6875.

(75) (a) Shang, R.; Ilies, L.; Matsumoto, A.; Nakamura, E. J. Am. Chem. Soc. 2013, 135, 6030. (b) Gu, Q.; Al Mamari, H. H.; Graczyk, K.; Diers, E.; Ackermann, L. Angew. Chem. Int. Ed. 2014, 53, 3868; Angew. Chem. 2014, 126, 3949. (c) Asako, S.; Norinder, J.; Ilies, L.; Yoshikai, N.; Nakamura, E. Adv. Synth. Catal. 2014, 356, 1481. (d) Ilies, L.; Matsubara, T.; Ichikawa, S.; Asako, S.; Nakamura, E. J. Am. Chem. Soc. 2014, 136, 13126. (e) Ilies, L.; Ichikawa, S.; Asako, S.; Matsubara, T.; Nakamura, E. Adv. Synth. Catal. 2015, 357, 2175. (f) Shang, R.; Ilies, L.; Nakamura, E. J. Am. Chem. Soc. 2015, 137, 7660. (g) Ilies, L.; Itabashi, Y.; Shang, R.; Nakamura, E. ACS Catal. 2017, 7, 89. (h) Schmiel, D.; Butenschön, H. Organometallics 2017, 36, 4979.

(76) Singh, P. P.; Aithagani, S. K.; Yadav, M.; Singh, V. P.; Vishwakarma, R. A. J. Org. Chem. 2013, 78, 2639.

(77) (a) Bistri, O.; Correa, A.; Bolm, C. Angew. Chem. Int. Ed. 2008, 47, 586; Angew. Chem. 2008, 120, 596. (b) Qu, X.; Li, T.; Zhu, Y.; Sun, P.; Yang, H.; Mao, J. Org. Biomol. Chem. 2011, 9, 5043. (c) Liu, X.; Zhang, S. Synlett 2011, 268. (d) Zhou, Q.; Su, L.; Jiang, T.; Zhang, B.; Chen, R.; Jiang, H.; Ye, Q.; Zhu, M.; Han, D.; Shen, J.; Dai, G.; Li, Z. Tetrahedron 2014, 70, 1125.
(78) Nakamura, Y.; Ilies, L.; Nakamura, E. Org. Lett. 2011, 13, 5998.

(79) (a) Fiandanese, V.; Marchese, G.; Martina, V.; Ronzini, L. Tetrahedron Lett. 1984, 25, 4805. (b) Scheiper, B.; Bonnekessel, M.; Krause, H.; Fürstner, A. J. Org. Chem. 2004, 69, 3934.

(80) Lv, J.; Ge, J.-T.; Luo, T.; Dong, H. Green Chem. 2018, 20, 1987.

(81) Savela, R.; Zawartka, W.; Leino, R. Organometallics 2012, 31, 3199.

(82) (a) Volla, C. M. R.; Markovic, D.; Dubbaka, S. R.; Vogel, P. Eur. J. Org. Chem. 2009, 6281. (b) Mayer, M.; Czaplik, W. M.; von Wangelin, A. J. Adv. Synth. Catal. 2010, 352, 2147. (c) Seto, C.; Otsuka, T.; Takeuchi, Y.; Tabuchi, D.; Nagano, T. Synlett 2018, 29, 1211.

(83) Sekine, M.; Ilies, L.; Nakamura, E. Org. Lett. 2013, 15, 714.

(84) Sun, C.-L.; Fürstner, A. Angew. Chem. Int. Ed. 2013, 52, 13071; Angew. Chem. 2013, 125, 13309.

(85) Echeverria, P.-G.; Fürstner, A. Angew. Chem. Int. Ed. 2016, 55, 11188; Angew. Chem. 2016, 128, 11354.

(86) Yoshikai, N.; Mieczkowski, A.; Matsumoto, A.; Ilies, L.; Nakamura, E. J. Am. Chem. Soc. 2010, 132, 5568.

(87) (a) Takacs, J. M.; Anderson, L. G.; Madhavan, G. V. B.; Creswell, M. W.; Seely, F. L.; Devroy, W. F. Organometallics 1986, 5, 2395. (b) Takacs, B. E.; Takacs, J. M. Tetrahedron Lett. 1990, 31, 2865.

(88) Atack, T. C.; Lecker, R. M.; Cook, S. P. J. Am. Chem. Soc. 2014, 136, 9521.

(89) Yoshida, T.; Ilies, L.; Nakamura, E. ACS Catal. 2017, 7, 3199.

(90) Labre, F.; Gimbert, Y.; Bannwarth, P.; Olivero, S.; Duñach, E.; Chavant, P. Y. Org. Lett. 2014, 16, 2366.

(91) Tamang, S. R.; Findlater, M. J. Org. Chem. 2017, 82, 12857.

(92) Kirihara, M.; Suzuki, S.; Ishihara, N.; Yamazaki, K.; Akiyama, T.; Ishizuka, Y. Synthesis 2017, 49, 2009.

(93) Kirihara, M.; Suzuki, S.; Ishizuka, Y.; Yamazaki, K.; Matsushima, R.; Suzuki, T.; Iwai, T. Tetrahedron Lett. 2013, 54, 5477.

(94) Weng, S.-S.; Ke, C.-S.; Chen, F.-K.; Lyu, Y.-F.; Lin, G.-Y. Tetrahedron Lett. 2011, 67, 1640.

(95) Quintard, A.; Rodriguez, J. Chem. Eur. J. 2015, 21, 14717.

(96) DeMartino, M. P.; Chen, K.; Baran, P. S. J. Am. Chem. Soc. 2008, $130,11546$.

(97) Hayashi, T.; Saski, K. Chem. Lett. 2011, 40, 492.

(98) Greenhalgh, M. D.; Kolodziej, A.; Sinclair, F.; Thomas, S. P. Organometallics 2014, 33, 5811.

(99) (a) Chopade, M. U.; Chopade, A. U. J. Chem. Pharm. Res. 2015, 7, 466. (b) Chopade, U. M.; Chopade, A. U.; Patil, H. S. Int. J. Curr. Res. 2016, 8, 28339.

(100) Pehlivan, L.; Métay, E.; Laval, S.; Dayoub, W.; Demonchaux, P.; Mignani, G.; Lemaire, M. Tetrahedron Lett. 2010, 51, 1939.

(101)Cettolin, M.; Bai, X.; Lübken, D.; Gatti, M.; Facchini, S. V.; Piarulli, U.; Pignataro, L.; Gennari, C. Eur. J. Org. Chem. 2018, in press; DOI: 10.1002/ejoc.201801348; and references therein.

(102) Knölker, H.-J.; Baum, E.; Goesmann, H.; Klauss, R. Angew. Chem. Int. Ed. 1999, 38, 2064; Angew. Chem. 1999, 111, 2196.

(103) Mancheño, O. G.; Bolm, C. Org. Lett. 2006, 8, 2349.

(104) Williamson, K. S.; Yoon, T. P. J. Am. Chem. Soc. 2010, 132, 4570.

(105)Wang, R.; Bao, W. Tetrahedron 2015, 71, 6997.

(106) Miranda, P. O.; Carballo, R. M.; Martin, V. S.; Padrón, J. I. Org. Lett. 2009, 11, 357.

(107) Chan, S. L.-F.; Low, K.-H.; Yang, C.; Cheung, S. H.-F.; Che, C.-M. Chem. Eur. J. 2011, 17, 4709. 